\title{
Anabases
}

ANABASES Traditions et réceptions de l'Antiquité

18 | 2013

Varia

\section{Le Jules César de Henry de Montherlant : dialogue avec une ombre}

Pierre Duroisin

\section{(2) OpenEdition}

1 Journals

Édition électronique

URL : http://journals.openedition.org/anabases/4438

DOI : 10.4000/anabases.4438

ISSN : 2256-9421

Éditeur

E.R.A.S.M.E.

Édition imprimée

Date de publication : 1 octobre 2013

Pagination : 131-173

ISSN : 1774-4296

\section{Référence électronique}

Pierre Duroisin, «Le Jules César de Henry de Montherlant : dialogue avec une ombre », Anabases [En ligne], 18 | 2013, mis en ligne le 01 novembre 2016, consulté le 20 octobre 2019. URL : http:// journals.openedition.org/anabases/4438 ; DOI : 10.4000/anabases.4438

(c) Anabases 


\section{Le Jules César de Henry de Montherlant : dialogue avec une ombre}

Pierre Duroisin

\section{Un manuscrit de la $\mathrm{BnF}$}

Parmi les manuscrits du fonds Montherlant de la Bibliothèque nationale de France repris sous la cote NAF 28165 se trouve une liasse de trente-cinq feuillets qui mérite une attention particulière. C'est un ensemble tout à fait cohérent mais à lire en deux temps. On a d'abord huit feuillets, constitués pour l'essentiel de notes de lecture sur des écrivains comme Platon, Épictète, Plutarque, Montesquieu (pour ses Considérations sur les causes de la grandeur des Romains et de leur décadence et pour son Dialogue de Sylla et d'Eucrate), Chateaubriand (pour ses Mémoires d'outre-tombe) et Stendhal (pour sa Vie de Napoléon), ou sur des historiens de l'Antiquité tels que Victor Duruy (pour son Histoire des Romains) et Ludwig Friedlaender (pour ses Mours romaines du règne d'Auguste à la fin des Antonins). On a ensuite, sur les vingt-sept autres feuillets, un dialogue en bonne et due forme qu'on n'aura pas trop de scrupules à intituler Jules César dans la mesure où c'est cela même qui figure, de la main de Montherlant, sur le premier feuillet du dossier liminaire ${ }^{1}$.

Un dossier dont il faut tout de suite retenir, pour deux raisons qui vont de pair, le Dialogue de Sylla et d'Eucrate.

1 On n'y trouve rien d'autre, sinon un 2 au crayon bleu. Le manuscrit est dans la boîte 5 , intitulée "Textes divers", du vaste ensemble NAF 28165 ; les notes sont foliotées de 1 à 8 , le texte est folioté de 9 à 35 . 
La première raison tient à une lettre que Montherlant avait envoyée à son ami Faure-Biguet en novembre 1917, alors qu'il était à Mirecourt, dans les Vosges, comme secrétaire d'état-major auprès du général de Castelnau : "J'ai écrit sept pages, lui disait-il en post-scriptum, sur le Dialogue de Sylla et d'Eucrate, qui lance des feux éclatants et sombres ${ }^{2}$."

Cette admiration ne fut pas éternelle. Quand l'auteur de Service inutile évoquera en 1929 "l'abdication " de Sylla, il dira aussi pourquoi il a refusé de faire une préface pour " le dialogue de Montesquieu ", parce que " ce morceau plein d'allure, délices de tout jeune homme bien né, est au fond creux et absurde ${ }^{3}$ ". N'empêche qu'en 1921, lorsqu'il écrit son Jules César, n'ayant du reste publié que La Relève du matin ${ }^{4}$, Montherlant est encore sous le charme. Sans doute s'est-il démarqué à plus d'un égard de son modèle. Montesquieu a fait se rencontrer le dictateur Sylla dans sa retraite de Tibur avec un philosophe imaginaire, alors que l'auteur de Jules César oppose l'ombre de César à un jeune interlocuteur derrière qui on reconnaîtra vite un certain Alban de Bricoule, héros d'un roman qui paraîtra fin 1922, voire un certain Henry de Montherlant, mais enfin le principe reste celui d'un dialogue où l'homme de pouvoir, dépossédé - pour quelque raison que ce soit - de ce pouvoir, est plus ou moins mis sur la sellette.

La tentation, pour Montherlant, de prendre exemple sur Montesquieu était d'autant plus vive que le dialogue est un genre qu'il a très tôt pratiqué. Ce n'est pas avec sa Reine morte de 1942, non plus que pour sa Pasiphaé de 1928, qu'il s'est essayé au dialogue. Sa première pièce, L'Exil, qu'il ne publia qu'en 1929, remonte à 1914, et si l'on y regarde d'un peu près, on voit que deux gros morceaux des Olympiques, à savoir La Leçon de football dans un parc et Les Onze devant la porte dorée, datés l'un de 1923 et l'autre de 1924, sont de longs dialogues; on voit aussi que le Dialogue avec Gérard de La Relève du matin remonte à $1919^{5}$ et que Le Jeudi de Bagatelle, autre dialogue bientôt ajouté en tête de La Relève, est d'octobre 1921.

2 Jacques-Napoléon FAURE-BIGUET, Les Enfances de Montherlant de neuf à vingt ans, Plon, 1941, p. 191. Le lieu d'édition ne sera pas mentionné dans ces notes quand il s'agit de Paris.

3 "J'ai le plaisir, ajoute-t-il alors, de trouver aujourd'hui dans Villemain ces paroles de Napoléon à M. de Narbonne : 'Qu'est-ce que c'est que, dans Montesquieu, cette conversation de Sylla et d'un sophiste grec ? Rien de cette pompeuse analyse des actes de Sylla n'est vrai ; et la faire admirer, c'est fausser les jeunes esprits" ", p. 620-621 dans le volume Essais de la Bibliothèque de la Pléiade, 1963, désormais désigné par la seule lettre E.

4 On ne parle ici que de livres, et non d'articles ou d'essais publiés dans les journaux et revues.

5 La Relève est de 1920, mais le Dialogue avec Gérard avait d'abord paru dans la NRF du $1^{\text {er }}$ août 1919. 
Allons plus loin et nous trouverons des dialogues de toute sorte dans ce que Montherlant a un jour appelé ses infantilia 6 .

La troisième des sept "nouvelles " qui composent le De Augusto, un recueil que le jeune Henry « publie » à douze ans, en 1907, est pour l'essentiel un dialogue à plusieurs voix : un gladiateur gaulois, un marchand de gemmes hébreu, un papetier étrusque, un poète ambulant, un cocher de char, des esclaves affranchis se lamentent, se querellent, s'insultent avant d'être interpellés par Auguste en personne. Même chose pour Nadia, un roman d'aventure en deux volumes qui " paraît » en 1907-1908 : les dialogues n'y manquent pas, qui opposent des Romains entre eux ou avec un colporteur gaulois ou avec un capitaine de vaisseau phénicien ${ }^{7}$. Même chose encore pour une nouvelle de 1909 intitulée La Charge où les protagonistes parlent une sorte de patois ${ }^{8}$. Le tout allant de pair avec une "comédie mythologique en quatre actes ", Les Dieux discutent, "publiée ", comme le De Augusto, en 1907 et dérivant d'" une nouvelle légèrement satirique " élaborée en $1906^{9}$. Montherlant, qui allait au théâtre avec sa grand-mère ${ }^{10}$, a pratiqué le dialogue à deux ou plusieurs voix bien avant d'en découvrir à l'école les formes savantes, et sa dette envers Montesquieu quand, à vingt-six ans, il écrit son Jules César tient d'abord à la tournure, disons dramatique de cette conversation entre un puissant qui n'est plus qu'une ombre et un jeune interlocuteur qui aurait pris dans la guerre la pleine mesure des choses.

6 Dans Enquête sur les maîtres de la jeune littérature de Pierre Varillon et Henri Rambaud, p. 106, note 1, Bloud et Gay, 1923.

7 Pour toutes ces œuvres de jeunesse, voir « Un inédit du jeune Henry de Montherlant : le chapitre I du De Augusto, 1907 ", "Le De Augusto du jeune Henry de Montherlant (suite et fin) " et "Henry de Montherlant auteur-éditeur de Nadia (1906-1908) " dans Les Lettres romanes, LXII, nº 1-2, p. 61-78, 2008, LXIII, n 3-4, p. 223-287, 2009 et LXV, $\mathrm{n}^{\circ} 1-2$, p. 87-150, 2011, UCL, mis en ligne par Brepols Publishers. J'y montre pourquoi il est permis de parler d'œuvres "publiées " par leur auteur.

8 Montherlant était assez fier de cette ouvre de jeunesse pour qu'il la fît paraître dans le numéro du 28 novembre 1934 de Vendémiaire et, une seconde fois, illustrée par PaulÉmile Lecomte, dans Paris 1943 Arts Lettres, p. 163-166 (publié aux PUf par les soins de la Ville de Paris, Inspection générale des Beaux-Arts).

9 C'est en ces termes que Montherlant en parlait à Faure-Biguet dans une lettre de septembre-octobre 1906 (voir Les Enfances, p. 29). Dans sa version dialoguée, l'œuvre ne manque pas d'ambition : onze divinités réunies autour de Jupiter, une armée de figurants (faunes, satyres, nymphes, chevaux ailés, etc.) et un décor représentant l'Olympe avec des trônes, des palmiers, un bassin, des cygnes... (voir mon article "Avant Thrasylle " dans les Actes à paraître chez Honoré Champion du colloque Lire Montherlant organisé en 2010 à Paris 3).

10 On lit dans ses carnets de 1965 une anecdote touchant une représentation de Monsieur de Pourceaugnac que sa grand-mère l'avait mené voir quand il avait "une dizaine d'années " (Tous Feux éteints, p. 23-24, Gallimard, 1975, et sa variante dans l'Index biographique, p. LIII, du volume Théâtre de la Bibliothèque de la Pléiade, désormais désigné par la seule lettre T). 
Cela admis, pourquoi Jules César plutôt qu'un autre ? Le lieu n'étant pas de s'étendre sur l'image fluctuante que Montherlant se fit du divin Jules entre ses dix ou douze ans et son grand âge ${ }^{11}$, on s'en tiendra ici à la période 1906-1921.

Pour qui considère l'œuvre publiée, le premier éclairage viendra des Bestiaires. Et plutôt des Bestiaires, édités en 1926 et datés par l'auteur de 1911 et 1925, que du Songe, édité en 1922 et daté de 1919-1922 ${ }^{12}$, parce qu'on y découvre le double du romancier, l'Alban précédemment évoqué, en 1909, au moment où il " termine sa quatrième dans une petite "boîte" d'Auteuil ${ }^{13}$ ", alors que dans Le Songe, où il apparaissait comme engagé volontaire, il avait neuf ans de plus. On apprend donc par Les Bestiaires que le jeune garçon vouait à Jules César une "dévotion " propre à le soutenir jusque dans les plus menues circonstances (il se consolera d'un mauvais déjeuner parce que, comme son modèle, il "mangeait de tout ${ }^{14}$ ») et qu'il avait été heureux de découvrir, s'étant lui-même pris de passion pour la corrida, que c'était César qui l'avait introduite à Rome ${ }^{15}$.

En quoi l'on aurait tort de voir seulement de la fiction, les infantilia étant à nouveau là pour nous révéler tout l'intérêt que le jeune Henry portait à la figure de César. À preuve cette Nadia déjà citée où, par l'entremise de ses personnages, l'écrivain en herbe débat de la culpabilité de Brutus comme le fera en 1965 l'auteur plus que chevronné de La Guerre civilee ${ }^{16}$ :

"Brutus a tué César, et pourtant tout le monde le croyait honnête. César croyait Brutus ami fidèle et Brutus était un ingrat...

- Qui ne l'est pas... mais Brutus était, quoi que l'on en dise, un vrai ami et non un ingrat... Rome souffrait, Brutus a compris sa souffrance et il a tâché de l'apaiser... il a sacrifié ses intérêts personnels aux intérêts publics, c'était un noble cœur...

- Quoi ! tu soutiens Brutus; tu blâmes donc Antoine ? toi ! un Romain !...

11 Cf. ma communication "Un Jules César entre le rêve et la réalité ", lors du colloque "L'imaginaire de Montherlant : figures et formes » organisé en novembre 2012 à l'Institut catholique de Paris par M. P. Brunel.

121911 tient au fait qu'ayant découvert la tauromachie en 1909 , lors d'un pèlerinage à Lourdes avec sa grand-mère, Montherlant s'y fera initier deux ans plus tard à l'occasion d'un voyage dans le sud de la France. Il est par ailleurs avéré qu'il avait commencé de prendre des notes pour Le Songe dès 1918, même s'il en situe la rédaction entre 1919 et 1922.

13 P. 385 dans le volume Romans et auvres de fiction non théâtrales de la Bibliothèque de la Pléiade, qui sera désormais désigné par l'abréviation R1.

14 R1 395. Plutarque (Vie de César, 17, 9) et Suétone (Caes., 53, 2) sont d'accord pour montrer un César tellement indifférent à la nourriture qu'il affecte de se régaler d'une huile rance que lui sert un hôte peu attentif.

15 R1 513. C'est Pline l'Ancien qui le dit (VIII, 70, 6), mais l'auteur des Bestiaires a pu le lire à l'article " tauromachie » de l'un ou l'autre dictionnaire encyclopédique.

16 Où il s'étonne du " parti, pris et maintenu contre vents et marées, que Brutus est quelqu'un de très bien" ( $\mathrm{T} 1310)$. 
- Ne te fâche pas, ami très cher, je ne blâme pas Antoine, il a fait son devoir, mais Brutus et Cassius ont fait plus que leur devoir - ils en sont morts, du reste... »

Autre précédent, une nouvelle du De Augusto intitulée Le Cri des vagues où l'on voit Auguste se promener sur la grève et contempler, rêveur, "le remous de l'Océan ». Des flots monte un gémissement, qui s'enfle jusqu'à gronder à l'égal d'un tonnerre. L'empereur se penche, "comme s'il voulait surprendre le secret des abîmes ", et ce qu'il entend le terrifie : Cave!, "Prends garde!", disent les vagues. Mais là où les choses se pimentent, c'est avec la version revue de cette nouvelle, devenue La Voix des vagues. L'avertissement n'a pas changé : Cave! Le promeneur solitaire, en revanche, a changé de nom : "La veille même de son assassinat, Jules César se promenait, seul, sur la grève... " Qu'on la situe fin 1907 ou un peu plus tard, la version revue du Cri des vagues traduit bien l'espèce de fascination qu'exerça très tôt sur Montherlant le personnage du divin Jules. Reste à savoir de quand date cette fascination.

On ne saurait invoquer, malgré tout l'effet qu'il eut sur son jeune lecteur ${ }^{17}$, le Quo vadis découvert en 1904, vu que Quo vadis se situe sous Néron. La réponse serait plutôt dans la correspondance qu'échangèrent Montherlant et Faure-Biguet, tous deux élèves à Janson de Sailly, durant l'été 1906.

Voici d'abord ce qu'on apprend par une lettre du début août : "Je lis Tite-Live, Histoire de Rome. J'ai dévoré les commentaires césariens et je commence l'Iliade 18 ", qui manque de précision mais semble prolonger le cours d'histoire que notre écolier avait eu, peu avant, à Janson, ou du moins les pages que son manuel, l'Histoire de l'Antiquité d'Albert Malet à quoi il restera continûment attaché ${ }^{19}$, consacrait à César et à la conquête des Gaules. On a de toute façon du plus solide avec une autre lettre de ce même mois d'août 1906 :

"Je viens de lire un livre romain, la Petite patricienne (librairie A. Mame, 3 francs), par

Henri Guerlin, illustré par M. Pille. [...]

Je te le recommande, les livres romains sont si rares.

J'en commence un autre, l'Époppée (sic) de César (même librairie, même auteur).

Les illustrations sont très jolies ${ }^{20}$."

J'ai montré ailleurs à quel point ces deux livres de Guerlin avaient influencé l'écriture du De Augusto, mais c'est évidemment L'Épopée de César qui nous intéresse ici.

Malet voit César comme "un despote bienfaisant " et vante " la douceur de son caractère $^{21}$ ». Guerlin est moins généreux, mais enfin ce " conquérant-type » comme il

17 Voir ce qu'en dit l'auteur du Treizième César, p. 145 notamment, Gallimard, 1970.

18 Les Enfances de Montherlant, p. 24.

19 Voir Port-Royal et le puritanisme romain (T 921) et Poissons dans Coups de soleil, Paris, Gallimard, 1972, p. 186.

20 Les Enfances de Montherlant, p. 27.

21 Histoire de l'Antiquité, p. 368, Hachette, s. d. 
appelle César, cet homme sans scrupules, cruel parfois, prodigue, avide, et qui tombe sous le charme d'une prêtresse gauloise, est aussi celui qui, avant de "se draper avec grâce dans sa toge " pour aller vers où l'appelle son destin, a tendu lui-même à Brutus "le poignard sacré avec lequel, souverain pontife, il accomplissait les sacrifices" $"$ ". Malet, n'étant pas romancier, dit plus sobrement qu' "à la tête du complot se trouvait Brutus, neveu de Caton, que les historiens ont représenté comme un homme vertueux et intègre, mais qui, obligé de César, et traité par lui comme un fils, oublia les bienfaits du dictateur et le poignarda ${ }^{23}$ ". C'est tout le débat que Montherlant va transposer dans Nadia et qu'il avait du reste retrouvé dans le Jules César de Shakespeare quand il était allé le voir mis en scène par Antoine ${ }^{24}$.

Mais l'intérêt de ces bribes exhumées de l'enfance n'est pas que d'authentifier le portrait que le romancier des Bestiaires a brossé de l'écolier Bricoule vénérant César (et par ricochet le portrait que le romancier du Songe avait brossé du guerrier Bricoule vénérant de même César), il est aussi d'expliquer pourquoi en 1921, lorsqu'il rédige un dialogue à la Montesquieu, Montherlant porte son choix sur le divin Jules. En faire une ombre qui remonte des Enfers après on ne sait quel sacrifice (souvenir évident du chant XI de l'Odyssée, quand Ulysse suscite l'ombre du devin Tirésias) témoignait d'ailleurs d'une belle habileté. Ce César de qui le Sylla de Montesquieu disait avec les mots que lui prête l'histoire : "Je ne crains qu'un homme dans lequel je crois voir plusieurs Marius $^{25}$ ", n'est plus, c'est le cas de le dire, que l'ombre de ce qu'il fut.

Dernier point à régler : d'où vient qu'on a pu dire d'entrée de jeu que le texte est de 1921, étant admis que les notes lui sont forcément antérieures? Les arguments sont de deux ordres : extrinsèque et intrinsèque.

Extrinsèque dans la mesure où Montherlant avait coutume d'écrire sur tout ce qui lui tombait sous la main, ce qui bien souvent donne d'irréfutables terminus a quo. Ils sont en l'occurrence fournis par trois documents : une lettre du 3 janvier 1921 où une parente remercie son "cher Henri " (sic) de l'intention qu'il a d'intervenir auprès du maréchal Pétain pour que le nom de son cousin Pierre de Riancey soit repris dans la liste des "tués devant Verdun ${ }^{26}$ "; une publicité de la maison West End Tailors

22 Op. cit., p. 283 dans une édition sans date de Mame, avec des illustrations de Marcel Pille, vendue $1,50 \mathrm{~F}$.

23 Histoire de l'Antiquité, l. cit. On retrouvera l'" obligé " de Malet sous la plume de Montherlant dans ses Notes de 1965-1966 sur La Guerre civile (T 1348).

24 "Je crois n'avoir manqué aucune des représentations de Jules César qui ont été données à Paris depuis près de soixante ans (la première étant le Jules César d'Antoine, que je vis à neuf ans) ", dira l'auteur de La Guerre civile (T 1353). Même si ce " neuf ans " est à prendre cum grano salis, le Jules César d'André Antoine datant de décembre 1906, on reste dans les parages de Nadia et on imagine l'émotion du jeune garçon retrouvant sur la scène et dans leur version shakespearienne les personnages qu'il connaissait par son Malet.

25 Cf. Suétone, Caes., 1, 3 et Plutarque, Vie de César, 1, 4.

26 Montherlant évoquera cette mort dans Service inutile (E 613). 
datée du 8 janvier ${ }^{27}$; une note du 18 janvier émanant de la rédaction de la revue L'Amérique $^{28}$.

S'y s'ajouteront les indices qui nous seront fournis au fil des pages par le texte lui-même. Un texte qui a les qualités et les défauts d'un brouillon - avec des ratures et avec des ajouts, entre les lignes, dans la marge ou sur des béquets - et dont on a donné, pour que la lecture en soit plus plaisante, une version quelque peu "nettoyée ${ }^{29}$ ». On y a toutefois inséré, en prévision du commentaire et sous la forme d'un bloc entre crochets droits, le numéro de la page en gras et celui du folio en italique, l'un étant de Montherlant, l'autre, de la BnF.

\section{Le dialogue avec l'ombre}

[1 9] - Je te salue, Jules César ${ }^{30}$. Que la nuit te soit propice. Les nuits appartiennent aux morts ${ }^{31}$.

" Je te vois donc! Je reconnais tes traits desséchés, ton front fuyant, la morsure de ta bouche aride. Tes yeux sont d'un bleu si clair qu'on ne peut pas les soutenir, -

27 C'est par le dossier NAF 17389 du fonds Montherlant qu'on peut y reconnaitre une lettre de West End Tailors.

28 Montherlant fut secrétaire général du Comité France-Amérique de 1920-21 à l'extrême fin de 1922. On n'a cité que les supports datés les plus récents, estimant qu'il ne servirait à rien, sinon pour l'anecdote, de citer les autres supports, lesquels vont du papier à en-tête des Assurances Générales Maritimes, où le futur écrivain travailla entre 1913 et 1915 (fos 9 et 21) à un billet du 12 novembre (1920 sans doute) par lequel un commerçant avise M. de Montherlant du passage d'un commis ( $f^{\circ} 26$ ), en passant par une liste $d^{\prime}$ ' anciens remèdes " du $\mathrm{D}^{\mathrm{r}}$ Banet pour se guérir d'un " gros rhume attrapé à la fin d'Août sur le champ de bataille de Verdun" (f f $^{\circ}$ ), une page d'épreuve du $\mathrm{n}^{\circ}$ d'avril-mai-juin 1920 de L'Amérique (f' 14 ), le programme d'un concert de Noël donné par la Manécanterie des Petits Chanteurs à la Croix de Bois ((fos 15 et 16) ou une lettre dactylographiée du 27 octobre 1920 émanant du Comité France-Amérique ( $f^{\circ} 23$ ). Pour les notes, on a trois indices : le folio 2 sur du papier à en-tête de l'Euvre du Souvenir des Défenseurs de Verdun, qui nous rappelle que Montherlant fut le premier secrétaire général de l'Euvre de l'Ossuaire de Douaumont dès 1920 ; le folio 3 au dos d'une lettre dactylographiée du Comité France-Amérique, et le folio 5 sur du papier à en-tête des Assurances Générales Maritimes, rien en tout cas qui incite à dater ces notes, comme on pouvait d'ailleurs s'y attendre, d'une autre année que 1920 ou du début de 1921.

29 On a signalé les corrections les plus intéressantes et encadré de chevrons quelques mots d'une lecture incertaine. Il faut par ailleurs savoir que l'édition de ce dialogue ne fut possible que parce que l'exécuteur testamentaire de Montherlant, $M$. Jean-Claude Barat, a tout de suite accordé les autorisations nécessaires et que la direction d'Anabases a bien voulu l'assumer malgré l'ampleur du projet. Comment ne pas leur en être reconnaissant ?

30 Ici une phrase barrée : "Ô démon de mon adolescence, il m’est donné enfin de te connaître!»

31 Ce « morts » a remplacé « dieux ». 
cernés de nacre, bordés de rose, comme si tu n'avais plus de cils. Je vois bien que tu as peu dormi. Des deux côtés de ta bouche sont les plis de ceux qui ont beaucoup serré les dents dans la volonté ou dans la fureur.

"Tu m'as soutenu et tourmenté tout le long de mon adolescence, quand l'histoire romaine déferlait en moi comme une mer. À dix ans je plaçais ton image sur le petit autel de ma chambre d'enfant, entre la Vierge et les saints. À quatorze ans, au collège, auprès de mes vertueux amis, je t'ai contrefait dans le drame de Shakespeare. À dix-huit ans ${ }^{32}$

Tu as été sans cesse à côté de moi. Quel bonheur que tu aies été malade, et dû te faire porter pour [2 10] échapper à Sylla! À cause de tes maux de tête, je n'avais plus honte des miens. La lenteur de ton avancement me guérissait de mes impatiences. Ta parole à Metellus m'a éclairé la guerre d'une lumière éblouissante : "Le temps des armes n'est pas celui des lois."

" Mais pourquoi es-tu venu, pour la première fois, si tard dans ma vie ? Il y a eu hier un quart de siècle que j'existe, et on ne ferait pas le quart d'une journée avec les heures où j'ai vraiment vécu. - Allons, ce n'est pas pour moi que te voici.

"Peut-être as-tu entendu quelque part sur le monde un peuple qui trouve que la mesure est comble, et appelle pour le sauver un dictateur. Et tu en as tremblé, de souvenir.

- Je n'ai pas plus entendu d'appel dans ce peuple dont tu parles, que je n'avais entendu d'appel dans le peuple romain quand je suis venu.

" Pas plus que n'en entendit Brutus quand il vint.

- Des hommes qui soient amoureux d'elle, voilà ceux dont ma patrie a besoin. Non de ceux qui ne songent qu'à eux-mêmes comme tu fis.

[3 11 - J'ai songé à moi-même, et proclame que je l'ai fait parce que je savais que la grandeur de mon âme subsisterait $[s i c]$ aux dangers du pouvoir ; et cette considération suffirait à me laver des injustices et des désordres où j'ai dû me résoudre pour y parvenir. J'ai dû contrarier ma nature pour ces valeurs, comme on doit courber les branches basses des arbres pour pouvoir y cueillir le fruit. Tu ne sais pas la douceur de mon cœur. Mais il y a plus.

" Je ne souhaiterai pas aux hommes de cabinet qui me reprochent mes illégalités, d'avoir sur leurs mains la dixième partie du sang qui se serait versé si j'étais resté dans la $\mathrm{loi}^{33}$.

32 La phrase est incomplète.

33 Ici une phrase barrée : "Au surplus tu sais que j'étais de naissance hors la loi.» 
$-34$

- Aujourd'hui je vois ton pays dans de grands tourments, et je suis en mesure d'en juger par ceux qui exercèrent le mien dans le temps que j'étais à sa tête, comme dans les temps qui vinrent après et que j’ai connus des lieux où je suis. Dans ces temps-là, l'amour de la patrie s'était épuisé par l'excès même où il s'était élevé au cours de la seconde guerre punique, sous la menace de l'envahisseur : la passion trop tendue s'était relâchée, ne laissant plus qu'une patience ignominieuse à tout souffrir[ $\left[\begin{array}{ll}4 & 12\end{array}\right]^{35}$. En haut s'était formée une ploutocratie de butors née en partie des hasards de la guerre, en partie de brigandages d'argent effrénés ; en bas un prolétariat de mendiants satisfaits, regardant comme un droit de vivre aux frais de l'État, y vivant d'ailleurs, et y vivant bien ; entre les deux, sacrifiées, vivotaient et luttaient une petite bourgeoisie durement atteinte par la cherté inouie de la vie, et une aristocratie de talent et de vertu dont le prestige s'évanouissait à mesure que s'établissait le règne de l'or. Le dégoût de la religion avait entraîné le dérèglement des mœurs (encore que l'histoire l'ait grossi). L'afflux des étrangers avait corrompu l'unité d'âme de la ville. Les provinces pressurées ne suffisaient plus à entretenir un trésor que vidait à mesure la charge épuisante de l'armée. Au travers de tout cela, [ 5 13] malgré les édits, malgré les encouragements et les peines, les distinctions aux mères de famille et les impôts sur les célibataires, la natalité baissait. Et cependant ce peuple magnanime, qui se défaisait sans avoir été défait, dans ce moment vivait encore, voulait encore être grand et faire face, soutenu qu'il était par son passé comme par des étais qui l'empêchaient de s'effondrer. Déjà il était marqué par la mort, mais son cœur trouvait encore assez d'amour pour [se] lamenter sur Germanicus ; sa grande âme enfantait le stoïcisme ; son intelligence créait l'administration provinciale ; et son vieux génie militaire veillait avec les légions fidèles depuis les rivages d'Irlande jusqu'aux flots noirs de la Baltique. J'en ai assez dit. Je parlerais sans fin si je voulais te représenter dans le détail comment ton pays et le mien, au-delà de toutes les différences que tu sais, ont convenance par génie.

[6 14 [ ] Je t'ai vu dans ta seconde adolescence, portant encore au cou la bulle d'or, mais déjà pareil à " ces maigres et ces pâles » qui firent ma crainte, quand j'eus dépassé le tragique de ma vie. La démesure entre ce que tu avais et ce que tu voulais mettait en toi un tremblement et presque une suffocation perpétuels. $\mathrm{Tu}$ secouais l'avenir au-dessus de ta tête comme une botte de foin enflammée. Comme moi, tu criais tes espérances, afin de te couper les retraites, et ton effronterie n'était qu'un moyen de te préserver contre toi-même. Tes actes de foi faisaient mal à ceux qui t'aimaient comme s'ils t'avaient vu dans les chants et les rires lorsqu'ils ont pour mission de t'apprendre que ton père est mort. On craignait pour toi, en t'enviant.

34 L'interlocuteur de César devait ici prendre la parole, mais on n'a rien d'autre qu'un blanc après le tiret indiquant le changement d'interlocuteur.

35 Dans la marge : "Tous brûlent de se vendre." 
- Pas une fois le soin d'un de mes plaisirs ne contraria le soin de mon progrès, et j'ai descendu jusqu'au fond de la délectation, à la rage de mes ennemis, une scandaleuse maitrise de moi-même [sic].

- Jamais César n'agit dans la colère.

- Une amie me nommait « l'inenivrable».

- Jamais César ne compta d'une façon absolue que sur soi-même.

- Une seule personne ne m’a jamais manqué de parole : moi-même.

[6 $\left.6^{\text {bis }} 15\right]$ - Ah, qui a été plus loin que toi dans ce sacrifice réfléchi du présent à l'avenir, de la vie à la postérité ! Je sais de toi un mot sans limites, tel que moi je n'<ai> pas prononcé. Tu as dit : "Je ne cherche pas à être heureux. "

"...Je me souviens bien de ton visage dans ce temps. Il était dépouillé, <mordu>, car il avait macéré longuement dans un bain âcre fait de ta volonté et de ton désir, éclairé par ton mécontentement comme les visages des autres hommes ne sont éclairés que par la souffrance. Les muscles fins soulevaient la peau tendre, autour de ta bouche surtout, - pareils aux nervures des feuilles. Et ils serraient les dents, collant les lèvres, baissaient les paupières, pour cacher les secrets esprits dévastateurs qui sans cela eussent crié à tous : "Voici celui qui au jour du massacre devra être abattu le premier, coûte que coûte. " Ton âme fermait ton visage comme avec une clef. Il était bossué comme une armure.

[7 16] " Tel tu étais. Tu avais dix-huit ans. Tu es davantage pareil aux autres, aujourd'hui.

- Indifférentes [me] sont toutes injures et la tienne, semblables à l'eau sur un torse frotté d'huile.

- Ah, c'est qu'aujourd'hui j'ai cru percevoir que tu étais revenu de ces extrémités où je t'ai vu, et que se relâchait peu à peu toute cette industrie si bien tendue de ta politique. Si je ne me trompe pas, tu as cessé de caresser ceux que tu détestes. Tu ne résistes plus à ton goût secret de déplaire. Tu abandonnes les avantages que tu avais pris. Tu reprends les gages que tu avais donnés. Tes silences déconcertent : comme tu laisses passer l'une après l'autre toutes les occasions de te mettre en valeur, ceux qui ne te connaissent pas se demandent s'ils ne cachent pas le vide, mais ceux qui te connaissent te mettent à jour, et ils haïssent la suprême marque de dédain que tu leur donnes par ce silence. Quand tu sais et qu'on t'interroge, tu réponds : "Je ne sais pas. » Quand tu viens de lire et qu'on t'interroge, tu réponds : " Je n'ai pas lu. " J'ai cru voir cela, et j’ai soupiré dans la crainte que tu sois devenu moins exigeant. 
[7 $\left.{ }^{\text {bis }} 17\right]$ » Et c'est pourquoi je suis venu, non pour te répéter, comme l'esclave au triomphateur : "Tu es un homme "; mais pour te rappeler au contraire qu'après les promesses que tu nous as faites, tu n'as plus le droit de n'être qu'un homme. Dis-moi donc, oui ou non, si je peux te compter encore parmi les superbes.

[8] - Jules César, Jules César, petit garçon, qui viens à droite si je lui tends à droite un chocolat, à gauche si je le lui tends à gauche! Ô les tristes petits garçons, avec leurs désirs jusqu'aux larmes pour des biens qui ne sont pas des biens !

"Ils sont un peu ridicules, ils sont un peu agaçants, mais on ne les rudoie pas pour cela ; ni je ne te rudoierai non plus. Je te parlerai avec ma gentillesse, qui me tient lieu toujours de charité.

"C'est vrai, j'ai changé peut-être, avec la vie. Mais ce n'est pas la guerre qui m’a détendu un peu, en retour des excès qu'elle me demanda. N'est-ce pas cette espèce de paix criminelle en nous discréditant l'avenir ? Qui voudrait confier à cet avenir autre chose que la volupté ? Elle seule est éternellement assurée. Deux êtres au milieu de l'effondrement total suffisent à maintenir l'espoir de bonheur. Mais l'espoir de la puissance est bâti sur les nuées.

[8 18 ] " Cher, très cher est le prix qu'il faut d'avance payer ta gloire. Je ne te parle pas des combats et des coups qui sont les exercices de ma dureté. Mais la longue servitude, les ménagements et les compromissions, enfin ce supplice de donner son attention et son temps à des objets qui en sont indignes, ce supplice si cruel pour moi que j'ai préféré parfois aller au devant d'un échec plutôt qu'accepter l'effort et l'ennui de chercher à voir clair dans l'âme de mon ennemi ! Dieu ! prendre part à la discussion sur la fédération et le congrès! Imagine-les quand ils montent de ton : on dirait qu'ils en mangent, tellement ils trouvent cela important... Je suis annihilé. Mes sentiments de dégoût fonctionnent moins bien dans la société des pourceaux.

"Et si j'échoue... Songe que la tristesse de notre paix est d'avoir été si souvent dupés, songe que c'est par peur de sembler dupes une fois de plus que tant d'honnêtes gens, enragés, se jettent dans l'indélicatesse. Quel tragique calcul, si, sur mon lit d'agonie, je dois reconnaître que toute cette partie morte de ma vie a été sacrifiée pour rien! Quel déchirement de m'être crédité sur l'inconnu!

[9 19] » Admets enfin que je réussisse. Qu'est-ce que j'obtiens ? Rien que je ne mésestime. Je m'enflerais pour des honneurs que me donnent des hommes que je méprise ? Quelles lois pourrais-je violer que je n'ai violées cent fois, dans cet état de médiocrité d'où je te parle? Quels plaisirs nouveaux ? Je sais bien que dans la vie je ne trouverai rien de meilleur que ce que j'y ai trouvé. Tuer? Est-ce que je ne peux pas faire tuer comme je veux, impunément ? Des louanges? Je sais ce qu'elles valent, j'en ai assez donné. Des vengeances? J'attaque pour écarter un obstacle ; jamais pour des raisons de sentiment. Le repos? Je ne peux pas m’arrêter. Non, non, épargne-moi ce ridicule et cette monstruosité repoussante, de courir à perdre le souffle, sans trêve, refusant de vivre, jusqu'à tomber, jusqu'à me détruire, pour atteindre à quelque chose que je ne 
désire pas. Cette folie peut être celle des martyrs fabuleux dans ton Érèbe ; elle serait la honte d'un homme libre.

- Détruis tous ces mobiles. La satisfaction de ton orgueil suffit seule à justifier tes tourments.

- Tu es naif. L'orgueil glisse comme l'huile : comprime-le ici, il se gonfle là. Serais-je infime ou magnifique, la quantité n'en saurait changer qui fut versée dans ma nature. S'efforcer de tout obtenir, refuser de rien obtenir, tout m'est bon pour délivrer mes cris.

[10 20] Que ma langue pourrisse dans ma bouche, si elle ne débite que des axiomes de manuel. Ces choses-ci ne coulent pas de mes lèvres, mais de la partie la plus secrète de ma vie : elles sont chaudes et profondes comme mon sang. Mais, puisqu'il paraît que les morts savent tant de choses, tu dois savoir que mes actes témoignent de la vérité de ce que je dis.

" Je m'amuse de ta perplexité. Comme un lutteur reste un long temps immobile, bras ballants, devant son adversaire, prosterné, car il ne sait plus quel coup tenter contre celui-là qui toujours glisse et lui échappe, et si pesamment enfante-t-il ses pensées $<$ qu'on> croit les voir qui se forment, sous le front bas, dans le cerveau bovin ; ainsi tu réfléchis, ne sachant plus par où me prendre, et c'est justement, car je suis imprenable.

"Quoi que je recherche, si c'est son contraire qui se présente, ave, donc, pour son contraire. Il n'est rien de ce que j'aime dont à l'instant je ne puisse me priver pour jamais. Que la ruine descende sur mon toit, un monastère me donnera la vie pour laquelle je suis fait. Que la justice des hommes me jette en prison, la prison, en m'isolant de la société, me permettra de l'aimer mieux que je ne pouvais faire dans son sein. Le froid, le chaud, la faim, la soif, l'injure sont sur moi comme sur un homme de pierre. Donne-moi la $\left[10^{\text {bis }} 21\right]$ maladie, elle remplacera les pratiques que je m'impose pour exercer ma volonté ou ma constance. Donne-moi la mort, elle m'indiffere, plus d'une fois j'ai connu une sorte de désir d'elle, dans le seul but de faire, à notre pauvre troupeau d'affolés, comme une démonstration de ce que peut être la mort d'un homme qui a sa raison (mais tu sais cela, ton monde a su mourir avant le nôtre).

- Ta liberté me fait peur.

- Mais tu la comprends. D’autres me détestent comme des esclaves peuvent détester un homme qui est libre, et ceux qui ont besoin celui qui n'a pas besoin.

- Esclaves parce qu'ils désirent ? Et toi aussi tu es esclave, qui ne désires pas.

- Ah, je ne sais si je ne désire rien ou si je désire tout. 
- Je hais la fausse fierté de paraître vaincre en se <désistant>. Je préfere une vertu corrompue par les mauvais alliages à celle qui n'a pas été à l'épreuve. C'est l'orgueil [11 22] des faibles, que l'immobilité.

- C'est la volonté des faibles, que l'espérance.

- Si se gagne la vie du corps en mangeant, si la vie de l'âme en espérant.

- Comme il est beau de ne pas espérer! Comme il est beau de n'attendre pas de récompense !

" Je donne ma vertu pour rien. Je ne puis plus souffrir la pensée d'être payé.

"Parfois je me sens pareil à une haute montagne de neige, éclatante, inaccessible. Je n'ai plus conscience de ma vie que par cela qui se détache d'elle - des affections, des aversions, des espoirs, des souvenirs - : ainsi des parcelles de sa neige se détachent du mont, avec un si petit bruit! Alors je te revois lorsque sous les coups d'épée "trainnant ton corps de côté et d'autre en poussant de grands cris, tel qu'une bête féroce assaillie par les chasseurs ${ }^{36}$ » (misérable dieu, tu avais donc bien peur de mourir !), tu vis Brutus qui venait sur toi. Enfin tu fis un geste d'homme, tu te couvris la tête de ta robe, et cessas de te défendre. Voilà pour moi le geste de ta vie.

[12 23] - Le geste de ma vie est celui que j'eus quand, briguant la place de grand pontife, je quittai ma mère le jour de l'élection avec cette parole : «Ce soir tu me verras grand pontife ou banni. " J'ai dit cela. Tant j'avais faim de cette ombre!

"Ça, brisons. Nous ne parlons plus la même langue. Si c'est la vérité que tu as atteinte, elle t’a pétrifié dans son embrasement. Tu t'es fait crevette en devenant dieu. Les mottes de terre diraient ce que tu dis, si elles parlaient.

"Mais dieu ! qui t’a nommé dieu ? Toi-même tu t'es nommé dieu ! Et tu es content ainsi ! Ô profond ridicule de ta vie intérieure! Moi, c'est un peuple de soixante millions ${ }^{37}$ d'hommes qui, par la voix du sénat, m'a décerné les honneurs divins.

" Ô impuissant! Ô crevette insensible ! Ô Grec perfide qui prétends faire mettre un diadème à ta lâcheté !

$\left[\begin{array}{ll}14 & 24\end{array}\right]^{38}$ - J'ai mon sang, Jules César, mon sombre sang chargé de " naphte ", et pourtant pur, et pourtant éclatant de couleur, comme le prisme insupportable sur la cime du plus haut glacier.

36 Ici un appel de note et cette note en bas de page : "Plutarque ».

37 « 60 millions » a remplacé « $200.000 »$.

38 Il n'y a pas de page 13. 
"Tu ne m'as pas laissé finir. Tu n'as pas laissé dire ${ }^{39}$ comment, du haut de mon esprit, j'ai fait sa part à mon sang. Mon sang! Je n'ai pas des mains pour boucher les plaies d'où tu coules, mais pour les élargir, ces plaies. Quoi, César, tu as cru que je pouvais me refuser l'amertume des victoires et la splendeur des échecs, et le ruissellement de la douleur, et l'obstacle, et la fraîche haine : tout le bien et le mal dévorants ?

[14 $\left.{ }^{\text {bis }} 25\right]$ " Et j'ai le pli au fond de ma chair qui est d'aller contre la nature. Ma vertu n'est pas la vertu morale. Tu le sais, toi : virtus veut dire force. Ma vertu est l'exercice de ma force, et il n'en est pas d'exercice plus journalier que celui de violenter la nature ${ }^{40}$.

"Pour cette raison de mon sang et pour cette raison de ma vertu, ne crains pas que je m'abandonne comme les inertes. Mais une chose est de se faire jouer par les objets extérieurs, et une autre chose de jouer avec eux.

[15 26] » Dans l'Iliade, Diomède se rue sur Énée bien qu'il sache qu'Apollon rend Énée invulnérable. Hector prédit la ruine de sa patrie, la captivité de sa femme avant de retourner se battre comme s'il croyait en la victoire. Quand le cheval prophétique annonce à Achille sa mort prochaine : "Je le sais bien ", répond-il, mais au lieu de se croiser les bras et d'attendre, il se rejette et tue encore d'autres hommes dans la bataille. Ainsi je vis, sachant la vanité des choses, mais agissant comme si j'en étais dupe, et jouant à faire l'homme dans la mesure où je gagne à ce jeu.

"Si j'ai un fils ${ }^{41}$ quelque jour (béni le jour où sur ma porte j'attacherai la couronne d'olivier!), si j'ai un fils, crois-tu que je ne saurai pas, tout le temps de sa première jeunesse, qu'un jour viendra où nous serons des ennemis l'un pour l'autre ou des gens qui ne [16 27] savent pas quoi se dire. Et pourtant cela m'empêchera-t-il d'agir en tout avec lui comme si notre amitié devait être éternelle et de faire les gestes de la sécurité, dans l'instant même où je serai glacé par l'avenir ?

"Quand tu jouais à la paume, ou quand nous jouons au ballon ${ }^{42}$ nous faisons notre possible dans le jeu, et un sauvage qui nous verrait croirait que nous accomplissons des choses très importantes : mais nous nous savons qu'au fond cela n'a aucune importance, que si nous perdons la partie rien dans notre vie ne sera changé ce soir et que nous en serons quittes pour un léger ennui, pareil à une petite bulle. Tout le jeu a été à la surface de nous. Nous nous y sommes prêtés et non donnés. Ainsi je fais avec la vie.

"Tu me verras chercher à obtenir quelque chose et faire tout comme si j'en étais passionné, mais si je ne l'obtiens pas, cela m’est indifférent. Tu me verras bondir sous l'outrage et punir l'insulteur, mais dans la réalité l'outrage ne m'a pas blessé. Il n'est aucun de mes gestes $\left[\begin{array}{ll}17 & 28\end{array}\right]$ qui ne cache l'indifférence, aucune de mes phrases où ne

39 Sans doute pour "Tu ne m'as pas laissé dire ".

40 Dans le coin supérieur gauche de cette page 14bis : « et de la violenter stérilement ».

41 Au-dessus de " fils", on lit " garçon ".

42 Ce «ballon" a remplacé « foot ". 
soit sous-entendu : «Étant entendu qu'en réalité cela m'est égal. » Tu me vois les traits de tes acteurs tragiques, bouche tordue et yeux dilatés : regarde un peu de côté et tu apercevras derrière le masque mon vrai visage, qui sourit en levant les sourcils.

"Ces choses ne sont pas des choses de manuel. Elles baignent de toutes parts dans ma vie.

- Ce que je croyais me faisait bondir, mais ce que tu m'expliques m'attriste.

"Ou tu méprises les choses humaines, et, quoi qu'ait dit ma colère, ton attitude est digne de respect : mais alors méprise-les franchement et sans leur faire de concessions.

"Ou tu veux user d'elles ${ }^{43}$, et alors crains ta liberté d'esprit. Les choses humaines ne veulent pas être traitées par des philosophes ou des amateurs. Elles demandent qu'on s'y livre tout entier en y croyant. Si tu as en toi cette trop dangereuse faculté de t'abstraire d'elles, à la première traverse sérieuse qu'elles t'opposeront, tu rentreras trop facilement en toi-même, parce que ce geste que tels appelleront une dérobade, est pour toi. Je ne crois pas à des gestes d'a[da]ptation bien soutenus quand le cœur est calme.

[18 29] " Je tremble qu'un jour tu ne regrettes d'avoir voulu être à la fois le héros et le sage, garder la sérénité et garder les passions. Prends garde à ces conciliations ! Si tu réussis, sans doute, on te dira très grand. Mais si, ayant affadi ceci par cela, tu échoues, on dira que tu étais trop faible pour choisir et trop pauvre pour sacrifier : il suffit d'avoir un parti pris pour être loué d'avoir de la volonté. La vie se vengera cruellement de ce qu'il y a d'insultant pour elle dans cette concession hautaine que tu lui fais. Les hommes ne te sauront aucun gré d'avoir voulu te faire semblable à eux alors que tu fus créé dissemblable. Conserve tout ce que je te dis dans ton cœur.

- Ô Jules César, je donne aux hommes un témoignage d'amour au-delà duquel il est peu de chose, étant prêt à donner à leurs croyances et à leurs soins, alors que je n'y ai pas part, cette pleine et suprême mesure du sacrifice que c'est de sacrifier sa vie. Demain, le matin ou le soir, l'occasion peut me prendre. Déjà, les fronts des meilleurs sont marqués du signe terrible. [19 30] J'entends la guerre qui s'impatiente ; j'entends un quadrige éclatant piaffer derrière l'horizon rouge. Qu'elle m'appelle et je m'y abolis ! Ne me mets pas parmi les habiles. Renonçant à la vie et à mes fous plaisirs effrénés, sans témoins, sans regret, sans espérance, sans croire à rien qu'à l'inutilité de mon sacrifice je me précipite dans l'indifférence de l'avenir, pour rien d'autre que la perfection d'un acte pur. Oui, perdons-les l'une dans l'autre, mon indifférence et celle de l'avenir ! Après avoir feint d'avoir de l'ambition et je n'en avais pas, feint de souffrir et je n'ai jamais souffert, feint d'attendre et je n'attendais rien, je meurs en feignant de croire que ma mort sert, mais persuadé qu'elle ne sert pas, et proclamant que tout est juste.

- On ne peut pas aller plus loin dans le désespoir. 
- Mais c'est alors que tu vas voir se [20 31] faire le prodige de l'acte pur. Cette mort que j'ai voulue vaine ne sera pas vaine. L'acte pur que nous avons lancé dans l'obscurité de l'histoire, allume des constellations qui ne sont pas pour nous. Le patrimoine idéal offert à chacun de nous par le néant est formé de millions d'actes qui dans leur temps n'ont servi à rien. Tu as augmenté ton Empire, mais tes successeurs ont tout perdu. Il n'est rien de ce que tu as construit, avec tes prudences, tes sueurs, tes calculs, l'effort et la réussite de toute ta vie, qu'il n'ait été dans le pouvoir du plus incapable de tes successeurs de détruire, et qu'il n'ait en effet détruit en une heure ou en une seconde par stupidité ou par fantaisie. Tu as travaillé en pleine caducité, et davantage encore que les autres, peut-être, puisqu'il est d'expérience qu'un génie plus médiocre réussisse où un génie plus grand a échoué, et que tout ce qui subsiste un peu a été fait par des hommes de second choix. Et pourtant, c'est de cette somme de francs échecs et de victoires inutiles qu'est fait le don que tu as fait au monde. Nous autres, [ [21 32] nos gains de la guerre seront-ils maintenus ? On vient nous dire : «Au prochain coup Verdun sera pris ", ou : "Ils sont morts pour ceci et cela... mais ceci et cela n'a pas été obtenu à cause de la mauvaise paix, de l'incurie, etc. » Mais qu'est-ce que cela fait ? Chacun de leurs actes est entré dans le domaine où rien ne peut rien contre lui. Que l'océan recouvre la France, s'il épargne un seul homme qui pense et qui se souvient, le sacrifice de dix-sept cent mille morts n'aura pas été inutile.

"Cessons de nous disputer, mon César. Le froid de la fin de la nuit m'incline vers la tendresse humaine. Voici le jour cher aux hommes; le matin réveille le désir de la gloire, si douce au cœur des pauvres jeunes gens. Écoute-les! Il n'est pas une opinion sur le monde à laquelle ils ne préferent le monde...

- Nous n'avons pas vraiment disputé : la grandeur de mon âme me rend apte à tout comprendre. J'aurais seulement dû deviner plus tôt que tu n'étais si sage que pour être davantage insensé. J'ai pu douter de toi, mon louveteau aux dents blanches!

[22 33] - Quand je suis ainsi immobile et que je ferme les yeux, pourtant il me semble que je suis emporté sur une route vertigineuse, avec la vitesse du vent, et la route n'est pas bordée d'arbres, mais de flammes qui arrivent sur moi, <puis> défaillent, et toujours ainsi, toujours ainsi. Et il suffit que je prononce ces paroles seules, et il me semble qu'on ferme à mes poignets des bracelets de glace, et qu'un gant d'acier plonge dans ma poitrine, et me retire le cœur, et toutes mes choses vivantes ne sont plus maintenues à cause de ce vide, et elles subissent... Je ne sens pas autre chose quand, du fond de lâches secrets, soudain, à l'improviste, ma pensée vole vers la femme qui me plait ${ }^{44}$.

44 En marge : "Je sens comme un visage se renverser sur moi "; au verso : "Pour cacher les secrets esprits dévastateurs qui sans cela l'eussent signalé à tous : "Voici celui qui au jour du massacre devra être abattu le premier coûte que coûte" ", qu'on trouve à la p. $6^{\text {bis }}$. 
[23 34 - Pardonnée la femme qui t’a mis au monde, si c'est vraiment d'une femme que tu es né. Pour que la nature rompe au profit de l'un l'égalité qu'il y a parmi les hommes, il en coûte trop à tous les autres.

"Mais tu as dit vrai, c'est le jour. Une rose naît au fond de l'orient, glacée comme par l'aiguail nocturne. Il ne m'est pas permis de rester davantage.

- Reste encore un peu, démon. Tu ne sais pas comme je respire mieux, avec ta force à la gauche de ma vie, là où battent les plaisirs et les cours ${ }^{45}$. Je me meurs à côté de ce qui n'est pas grand. Mais non, tu t'en vas !... Laisse au moins que je te baise la main. $\mathrm{Si}$ je pouvais faire quelque chose pour toi !

- Les vivants ne peuvent rien pour les morts. Sers ma gloire, s'il te plaît. C'est tout.

- Adieu. Dans la guerre j'ai lutté contre la pensée de ma mort, jusqu'au jour où l'idée m'est venue que je te retrouverais là-bas ; dès ce $\left[\begin{array}{lll}24 & 35\end{array}\right]^{46}$ jour-là, j'ai accepté. Mais aujourd'hui je te dis d'une façon encore plus dépouillée : je suis consolé d'être mortel parce que tu le fus ; si jamais je dois avoir peur...

- Le néant ne fait pas mal. Adieu.

- César! Pauvre César! (L’ombre a disparu) Ô ma patrie, me voici seul avec toi.

\section{Dialogue avec l'ombre et avec soi-même}

Un rappel et une précision d'ordre pratique avant de passer au commentaire : $1^{\circ}$ c'est par commodité qu'on a donné au dialogue ce nom de Jules César que Montherlant a lui-même attribué à l'ensemble du dossier; $2^{\circ}$ on notera le passage d'une page ou d'un ensemble de pages à l'autre en reprenant le système de références utilisé dans le texte.

[1-2 9-10] L'entrée en matière est des plus directe. Montesquieu avait imaginé un court préambule qu'il avait mis dans la bouche de son Eucrate : "Quelques jours après que Sylla se fut démis de la dictature, j'appris que la réputation que j'avais parmi les philosophes lui faisait souhaiter de me voir... " Chez Montherlant, l'ombre est là, que le dévot accueille le plus simplement qui soit : " Je te salue, Jules César. » Une apostrophe fut même rayée par l'auteur : "Ô démon de mon adolescence !", qui était

45 En dessous de ces derniers mots, eux-mêmes ajoutés dans la marge, "du côté du plaisir et du cœur ", et plus bas: "Tu n'es pas pareil à une ombre, mais par la fraîcheur que tu répands, tu es pareil à une fenêtre ouverte. "

46 À côté de ce 24, un 23 et un 26 sur lesquels il serait vain d'épiloguer. 
pourtant chargée de sens, « démon » ayant ici son acception païenne. C'est son démon, en latin son genius, son génie, qui, à Rome comme en Grèce, veille sur tout un chacun, indéfectiblement lié à sa personne jusque dans la mort, et plus près (quoi qu'en dise ensuite l'interlocuteur de César : "Tu m'as soutenu et tourmenté tout le long de mon adolescence ») de l'ange gardien des chrétiens que de leur démon persécuteur. Et Montherlant ne l'ignorait pas : des notes de sa main qu'on trouve dans le fonds Montherlant du Musée Richard Anacréon de Granville prouvent qu'il avait lu avec une extrême attention les articles Daemon et Genius du Dictionnaire des Antiquités grecques et romaines de Daremberg et Saglio ${ }^{47}$. Quand le "démon " provisoirement éliminé resurgira tout à la fin de l'entretien, on verra clairement qu'il n'a rien de diabolique : "Reste encore un peu, démon. Tu ne sais pas comme je respire mieux, avec ta force à la gauche de ma vie, là où battent les plaisirs et les cœurs. "

La suite : "Les nuits appartiennent aux morts ", est un souvenir d'Hésiode, du vers 730 des Travaux et les jours pour être plus précis, d'où il ressort en fait que « les nuits appartiennent aux dieux ». Mais cela aussi Montherlant le savait bien, qui dans un premier temps avait cité le mot même d'Hésiode et le citera maintes fois dans son œuvre sans le travestir ${ }^{48}$.

Les yeux bleu clair de César sont pure invention, Suétone ayant vanté « les yeux noirs et vifs » du dictateur ${ }^{49}$ et Plutarque n'en ayant rien dit du tout. Le regard d'une ombre, il est vrai, n'est pas celui d'un homme de chair et d'os, et Montherlant n'a pas manqué de broder autour de ce masque de revenant.

Que dire de l'évocation des temps révolus : «À dix ans... À quatorze ans... À dixhuit ans... » ? Rien, forcément, de ce " dix-huit ans » qui nous aurait conduits à l'approche de la guerre s'il avait tenu sa promesse, et la prestation, à quatorze ans, devant les petits camarades pourrait être le lointain écho du Jules César d'Antoine qu'on a évoqué plus haut ${ }^{50}$. Mais c'est surtout avec l'autel des dix ans qu'on entrera dans l'intimité du narrateur, l'image de César entre la Vierge et les saints s'étant apparemment substituée, pour les besoins de la cause, à la statuette de saint Expédit, officier romain de son vivant, que le jeune Henry-Marie-Joseph-Frédéric-Expédite (puisque tels sont les prénoms de Montherlant) avait dans sa chambre à côté de celles du Sacré-Cœur et de la Sainte Vierge et qu'il reconnut bientôt, ainsi qu'on le lit dans les Malatestiana de 1969-

47 Ces notes se trouvent dans un dossier intitulé Notes Brouittons Guerre rassemblant de nombreuses notes de lecture des années 1920-1921.

48 Il le citera dans Numa, un essai qui a d'abord paru dans L'Intransigeant du 24 août 1927 (où le mot est justement attribué à Hésiode avant d'être imputé à Horace quand Numa sera repris dans Pour le délassement de l'auteur, p. 139. Hazan, 1928, et dans Coups de soleil, p. 21, La Palatine, 1950), et il le citera deux fois encore en 1938, dans la version revue des Olympiques (R1 323) et dans L'Équinoxe de septembre (E 820).

49 Voir Caes., 45, 1.

50 À quatorze ans, Montherlant était à l'école Saint-Pierre de Neuilly, où il fut d'octobre 1907 à l'été 1910. 
1970, comme l'image de la Rome païenne ${ }^{51}$. Ce laraire s'accorde bien, en tout cas, avec le mot des Bestiaires: "Alban avait une dévotion pour Jules César ", et symbolise dans toute sa précocité l'élan syncrétiste qui nourrira l'œuvre jusqu'à l'époque, ou peu s'en faut, de Trois jours au Montserrat. "Je rêvais sur Septime Sévère qui plaça l'image de Jésus au Panthéon ", dira le vieil écrivain en évoquant les années 20-21 ${ }^{52}$; il avait lui-même inversé le mouvement en rendant saint Expédit à sa romanité.

Bénir la maladie qui sauva le jeune César des griffes de Sylla, c’est aller nettement plus loin que ne le firent Plutarque ou Suétone ${ }^{53}$. Pour les maux de tête, en revanche, on a la pleine caution de Plutarque ${ }^{54}$, la question étant plutôt de savoir si Montherlant fut lui-même accablé par les migraines dont souffre, pour citer quelqu'un qui lui ressemble, l'Antonin de La Relève du matin ${ }^{55}$. Quoi qu'il en soit, "À cause de tes maux de tête, je n'avais plus honte des miens " est dans la ligne de ce qu'on a lu dans Les Bestiaires: "Heureusement qu'il mangeait de tout, comme Jules César, rapprochement qui le consola ", et c'est encore le réflexe qu'on découvre, mutatis mutandis, dans les carnets de 1963 et 1964, quand l'écrivain se console de mal dormir en se rappelant les insomnies d'Auguste ${ }^{56}$.

Plutarque et Suétone se retrouvent ensemble derrière « La lenteur de ton avancement me guérissait de mes impatiences ", qui, pour César, fait sans nul doute allusion à l'homme gémissant de n'avoir rien accompli de mémorable encore à l'âge où Alexandre avait déjà soumis la terre entière ${ }^{57}$. On sera plus circonspect touchant les impatiences de son interlocuteur, à moins d'y voir (toujours cette tentation de l'identifier à Montherlant) le reflet de dévorantes ambitions littéraires.

\section{$51 \quad$ Voir T 457.}

52 Mais aimons-nous ceux que nous aimons ?, p. 39. Montherlant reprenait ce qu'il avait dit dans Paysage des Olympiques: "Dans un syncrétisme éperdu, je rêvais sur Septime Sévère qui plaça l'image de Jésus au Panthéon " (op. cit., p. 43, Grasset, 1940), où déjà il confondait Septime Sévère (193-211) et Alexandre Sévère (222-235). Aucune confusion, en revanche, dans la note du 27 janvier 1954 qui fut reprise dans les carnets posthumes Garder tout en composant tout (voir p. 214, Gallimard, 2001).

53 César tomba malade alors qu'il tentait d'échapper aux sicaires de Sylla et fut même obligé, pour se tirer d'affaire, de les soudoyer (voir Suétone, Caes., 1, 2 et Plutarque, Vie de César, $1,5-7)$.

54 Voir Plutarque, op. cit., 17, 2.

55 E 153. Jules Roy évoquera dans son Journal 1925-1965, à la date du 15 juillet 1937, un Montherlant qui souffre de migraines (op. cit., p. 109, Albin Michel, 1998).

56 Voir Va jouer avec cette poussière, p. 128 et 155, Gallimard, 1966.

57 Une anecdote que Suétone et Plutarque situent l'un et l'autre en Espagne, mais le premier en 69-68, quand César avait reçu, à trente-deux ans, la questure de l'Espagne ultérieure (Caes., 7,1 ), et le second neuf ans plus tard et dans d'autres circonstances, quand il y exerça la propréture (Vie de César, 11, 5-6). 
On reste dans Plutarque avec la réponse de César à Metellus : «Le temps des armes n'est pas celui des lois ${ }^{58}$ ", mais on est aussi au cœur du Songe, et même doublement pour peu qu'on envisage la version originale du Songe, celle qui parut chez Grasset, dans la collection "Le Roman ", avec un achevé d'imprimer du 20 novembre 1922.

Il faut faire une première station au chapitre $\mathrm{V}$ du roman, quand Bricoule jubile de s'être évadé "d'une société qu'il échoue à s'asservir " pour rejoindre la "grande communauté du front, née à la hauteur des herbes et des eaux " :

" Et il se souvenait de la réponse faite par César au tribun qui lui reprochait de piller le trésor d'un temple, - de cette réponse profonde qui tant de fois allait lui apparaître comme une justification sans réplique : "Le temps des armes n'est pas celui des lois" ${ }^{9}$."

Il faut aller ensuite au chapitre XI, pour un passage qui sera éliminé de la version définitive, quand la victoire suscite chez le héros des idées de triomphe à l'ancienne (" le vrai triomphe césarien, avec les chefs ennemis enchaînés, avec les simulacres en métal de toutes les terres conquises ou reconquises... ${ }^{60}$ ") et que " l'antique geste de la prise de possession lui met dans le cœur un lancinant désir » :

"Tant le moindre événement nouveau lui était prétexte pour se croire tout permis. Si "le temps des armes n'est pas celui des lois", comme l'avait dit le divin Jules, que dire alors du temps de la victoire! La victoire émeut ses parties les plus nobles, mais après lui être apparue d'abord, et essentiellement, comme une facilité de plus accordée à la satisfaction sans bornes de tous ses instincts ${ }^{61}$."

De quoi donner sa pleine mesure à l'aveu du dialogue, « éclairer la guerre d'une lumière éblouissante " n'étant pas anodin.

La suite : "Mais pourquoi es-tu venu si tard dans ma vie ? Il y a eu hier un quart de siècle que j'existe... Allons, ce n'est pas pour moi que te voici », appelle deux remarques.

L'une concerne la date du dialogue. À prendre les choses au pied de la lettre, tout en considérant que Montherlant, né le 20 avril 1895, entretint sa vie durant la légende qu'il était né le 21 avril 1896, on pourrait en déduire (un peu naïvement, mais qui sait ?) que Jules César fut commencé le 22 avril 1921 et que d'entrée de jeu le texte confirme ce que disent les bouts de papier au dos desquels il fut écrit.

L'autre remarque a trait au fond. Le reproche qui est ici fait à César va déboucher sur une sorte de question qui plongera le lecteur dans la France de 1921 : «Peut-être

58 Vie de César, 35, 6. La traduction est sans doute celle d'Alexis Pierron.

59 On est dans le chapitre intitulé "Le Dansant de la Fête " (p. 72 de l'éd. originale ; R1 48).

60 P. 189-190 de l'éd. originale dans le chapitre intitulé "Mon compagnon... ». On a ici un écho de l'éloge de Stilicon par le poète Claudien (voir Pan., IV, 3, 46-48). La victoire qui a sur Alban de tels effets n'est autre que la contre-offensive alliée du 18 juillet 1918.

61 Ibid., p. 191. 
as-tu entendu un peuple qui appelle pour le sauver un dictateur. » On n'est pas si loin, en fait, du Montesquieu des Considérations, qui mêla volontiers l'histoire moderne ou contemporaine à celle de la Rome ancienne ${ }^{62}$, avec cette différence que Montherlant peut faire parler l'ombre de César comme Montesquieu n'aurait pu faire avec son Sylla ${ }^{63}$. S'il y avait, comme on l'a dit plus haut, de l'habileté à convoquer un César qui n'est plus que l'ombre de lui-même, il n'était pas moins habile de s'en servir comme du témoin parfait, celui qui, ayant vu défiler près de vingt siècles depuis le jour lointain de son assassinat, sait donc ce qu'il advint de Rome après sa propre mort et comment va le monde en 1921.

[3-5 11-13] L'ex-dictateur commence par se dérober (« Je n'ai pas entendu d'appel dans ce peuple dont tu parles "); on le voit ensuite qui se disculpe, comme avait fait Sylla devant Eucrate ; il brosse enfin de sa Rome un tableau où la société de l'immédiat après-guerre a selon lui toutes les chances de bientôt se reconnaître :

"Aujourd'hui je vois ton pays dans de grands tourments, et je suis en mesure d'en juger par ceux qui exercèrent le mien... ${ }^{64}$ "

Pour brosser ce tableau, Montherlant a essentiellement puisé, comme il ressort des feuillets 7 et 8 du dossier liminaire, dans le tome $1^{\text {er }}$ des Mours romaines du règne d'Auguste à la fin des Antonins de Ludwig Friedlaender qui avait paru en 1865 chez Reinwald, dans la «traduction libre » de Charles Vogel, avec de copieuses Considérations générales du traducteur.

Reproduire les quatre pages de notes ne serait pas très utile ; on en retiendra les passages que l'écrivain a lui-même retenus pour faire parler César :

62 Ainsi évoque-t-il dans le ch. VI les Espagnols après la conquête du Mexique et du Pérou, dans le ch. VIII le gouvernement de l'Angleterre, dans le ch. IX le canton de Berne, dans le ch. XI la France des guerres de religion, l'Angleterre sous Cromwell, les Perses contre les Turcs, etc.

63 De l'avenir, Sylla ne peut prédire grand-chose, exception faite, tout à la fin du dialogue, du mot qu'on a cité plus haut : "Je ne crains qu'un homme dans lequel je crois voir plusieurs Marius."

64 "Exercer" a ici le sens de " mettre à l'épreuve ", comme le latin exercere peut signifier «tourmenter». 
xxj. Les opérations qui enrichirent certains sénateurs étaient de l'usure ou de l'agiotage, non pas du commerce, ou se réduisaient à des spéculations sur les maisons ou les terrains

[xx] Déjà dans les derniers temps de la république romaine, les pauvres, s'habituant de plus en plus à regarder le droit de se faire nourrir par l'État comme leur apanage, durent s'avilir - corruption générale et irrémédiable - prolétaires mendiants [précédé d'un $\mathrm{v}$ dans la marge]

xxxvj. Les petits, la multitude ressentait moins directement l'effet d'iniquités que lui épargnait sa misère même. C'est la populace qu'on fêtait, au contraire, à laquelle on prodiguait des divertissements. [précédé d'un $\mathrm{v}$ dans la marge]

35 Vie la moins agréable $\mathrm{p}^{\mathrm{r}}$ classe moyenne ; cherté des vivres et objets $1^{\text {re }}$ nécessité

186 « D'où doit-il être permis qu'un homme venu à Rome avec le vent qui y apporte les prunes de Damas et les figues de Syrie... occupe à table une place d'honneur ? N'est-ce donc rien d'avoir respiré dans notre enfance l'air du $\mathrm{M}^{\mathrm{t}}$ Aventin et mangé les fruits de la Sabine ?" Juvénal III, 81 etc.

309 Auguste s'efforce d'encourager le mariage par des récompenses et distinctions aux gens mariés et aux pères de famille, ou des peines édictées contre les célibataires et les gens mariés dépourvus d'enfants
En haut s'était formée une ploutocratie de butors née en partie des hasards de la guerre, en partie de brigandages d'argent effrénés ; en bas un prolétariat de mendiants satisfaits, regardant comme un droit de vivre aux frais de l'État, y vivant d'ailleurs, et y vivant bien ; entre les deux, sacrifiées, vivotaient et luttaient une petite bourgeoisie durement atteinte par la cherté inouie de la vie, et une aristocratie de talent et de vertu dont le prestige s'évanouissait à mesure que s'établissait le règne de l'or. Le dégoût de la religion avait entraîné le dérèglement des mœurs (encore que l'histoire l'ait grossi). L'afflux des étrangers avait corrompu l'unité d'âme de la ville. Les provinces pressurées ne suffisaient plus à entretenir un trésor que vidait à mesure la charge épuisante de l'armée. Au travers de tout cela, malgré les édits, malgré les encouragements et les peines, les distinctions aux mères de famille et les impôts sur les célibataires, la natalité baissait. 
S'il est à peine besoin de souligner l'aisance avec laquelle Montherlant remodela ce qu'il avait en fin de compte retenu de sa première sélection ${ }^{65}$, deux choses au moins sont à relever dans l'exposé de César.

La première tient à l'espèce d'immortalité que lui confere son statut de fantôme. Quand le divin Jules, mort en 44 avant J.-C., dénonce les méfaits de l'immigration comme le fera cent cinquante ans plus tard un contemporain de Trajan et d'Hadrien, quand il constate que les efforts d'Auguste pour lutter contre la dénatalité furent vains, mais sans nommer Juvénal ni Auguste, on oublie vite qu'il prophétise à rebours. En revanche, quand il s'émeut à l'idée que le peuple romain, bien que déjà sur son déclin, " trouvait encore assez d'amour pour se lamenter sur Germanicus » ou que «sa grande âme enfantait le stoïcisme » ou que "son vieux génie militaire veillait depuis les rivages d'Irlande jusqu'aux flots noirs de la Baltique ", on voit tout de suite qu'il parle comme seule une ombre peut le faire, Germanicus étant mort en 19 de notre ère ${ }^{66}$, le stoïcisme auquel il pense étant probablement celui de Sénèque, d'Épictète et de Marc Aurèle ${ }^{67}$, et l'Irlande et la Baltique ne portant pas encore ces noms.

L'autre remarque concerne plus précisément le mot qui fut mis dans la bouche de César : "L'afflux des étrangers avait corrompu l'unité d'âme de la ville », pour dire en bref ce que Juvénal déplorait à grand renfort d'images dans sa troisième satire. C'est de cette même satire en effet que se souviendra, en 1923, l'auteur de Tibre et Oronte lorsqu'après en avoir cité deux vers emblématiques, il s'écriera : « La plainte de Juvénal est nôtre. On demande une digue contre l'Oronte ${ }^{68}$. " Ce ne sera pas, alors, pour dénoncer l'afflux des étrangers dans une France qui ne serait plus elle-même, ce sera pour défendre un « ordre du Tibre » menacé par une vision « féminine » du monde ${ }^{69}$, mais la coïncidence avec le dialogue de 1921 ne saurait être l'effet du hasard ${ }^{70}$.

65 Qu'il s'agisse de la préface de Vogel, reconnaissable aux chiffres romains notés à l'ancienne, ou du texte de Friedlaender.

66 S'agissant de la douleur des Romains à la mort de Germanicus, il y a fort à parier que Montherlant s'est souvenu du ch. XIV des Considérations, où Montesquieu évoque un peuple qui " ne sentait que son impuissance " : "Il était mal ; il plaça ses craintes et ses espérances sur la personne de Germanicus ; et cet objet lui étant enlevé, il tomba dans le désespoir. "

67 Plutôt que celui de son temps, les maîtres stoïciens pour un Romain du $\mathrm{I}^{\mathrm{er}}$ s. avant J.-C. s'appelant Panétius et Posidonius.

68 Iam pridem syrus in Tiberim defluxit Orontes / Et linguam et mores et cum tibicine chordas... Ce sont les vers 62 et 63 de la troisième satire que citait alors Montherlant, en omettant le secum vexit des vers 64 et 65 .

69 L'essai Tibre et Oronte, daté du 15 août 1923, "chapeaute " la Première Olympique dans sa version originale (pour le traitement ensuite réservé à cet essai, voir « Henry de Montherlant "entre deux mondes" : la leçon des manuscrits (I) ", p. 79-80, dans Anabases 16).

70 Friedlaender, même s'il ne cite pas ce passage de Juvénal, y fait allusion quand il écrit à propos de l'immigration, p. 289 : «Il semblait, comme dit Juvénal, que tout l'Oronte (le 
[6-6 ${ }^{\text {bis }}$ 14-15] Il fallait une transition qui permît à César de s'intéresser de plus près à son interlocuteur. Ce fut "Je t'ai vu dans ta seconde adolescence, portant encore au cou la bulle d'or, mais déjà pareil à "ces maigres et ces pâles" qui firent ma crainte... ", où il apparaît que Montherlant s'en est sorti avec un détail vestimentaire et une citation de Plutarque.

La bulle est bien sûr l'ornement suspendu au cou de l'enfant jusqu'à la puberté et contenant une amulette destinée à le protéger du mauvais oeil. Elle n'est d'or cependant, bulla aurea, que pour les enfants de la noblesse, étant de cuir pour ceux des affranchis ou des classes inférieures. Cela veut dire que l'interlocuteur de César est un aristocrate, mais le tour est d'autant plus subtil qu'il vaut sans doute aussi pour l'auteur, lequel veilla pendant longtemps à se présenter comme le comte de Montherlant. "Je n'ai nul droit, écrira-t-il le 15 mai 1957 à Philippe de Saint Robert, à ce titre de comte que vous me donnez, dont qq. ancêtres (au XVIII e siècle), mon père, et moi-même dans ma jeunesse, s'affublèrent fort misérablement ${ }^{71}$. "N'empêche qu'en 1921 il tenait assez à l'aristocratie de la gens Montherlant pour qu'il la signifie à son lecteur avec la bulle d'or ${ }^{72}$.

L'allusion aux maigres et aux pâles rappelle la réponse que fit le dictateur à ceux qui le mettaient en garde contre Antoine et Dolabella : " Je ne crains pas beaucoup ces gens gras et bien peignés, mais plutôt ces hommes pâles et maigres. "Il désignait par là, ajoute Plutarque, ses futurs assassins ${ }^{73}$, mais l'intérêt de ces pâles, sinon des maigres, sera aussi de nous ramener au Songe: " Je ne voudrais pas avoir des muscles courts, murmure la sportive amie de Bricoule, avec de longues aponévroses apparentes qui me feraient un écorché blanchâtre, bon pour ceux qu'Alban appelle les Pâles... », et

fleuve principal de la Syrie) s'était transvasé dans le Tibre », avec en note cette référence : "III, 58, etc. "

71 Voir Montherlant ou l'indignation tragique, p. 144, Hermann, "Savoir lettres ", 2012.

72 C'est avec ce titre encore que Montherlant figure, en tant que premier Secrétaire général de l'Euvre de l'Ossuaire de Douaumont, dans l'inscription, postérieure à 1932, qu'on trouve à l'entrée de l'Ossuaire. Beaucoup plus tôt, on a une lettre du fonds Montherlant de la BnF (boîte "Brouillons Vie » du dossier NAF 28165) envoyée le 9 septembre 1913 au "Count de Montherlant, Villa $S^{t}$ Ferdinand, Neuilly Seine, France» par «W. A. Mansell $\& \mathrm{C}^{\circ}$, Art Publishers and Photographers, 405 Oxford Street London W. " touchant le coût d'une reproduction du tambour de colonne sculpté provenant de l'Artémision d'Éphèse et conservé au British Museum. Est-ce encore la noblesse de sa famille que voulait souligner en 1958 l'auteur du Treizième César quand il écrivait : "Voilà ce que nous lisions dans Quo vadis, du temps que nous portions au cou la bulle d'or " (op. cit., p. 194) ? On penche plutôt pour la persistance de l'image.

73 Voir Plutarque, Vie de César, 62, 10, ainsi que Vie de Brutus, 8, 2 et Vie d'Antoine, 11, 6. On a donné la traduction d'Alexis Pierron, mais on croirait volontiers que c'est le Cicéron et ses amis de Gaston Boissier, très tôt pratiqué par Montherlant, qui attira d'abord son attention sur ce mot entre tous fameux dont Shakespeare lui-même fit bon usage. Boissier dit en effet «les maigres et les pâles» (op. cit., p. 350) quand Pierron, plus près du grec, dit " ces hommes pâles et maigres ". 
plus loin c'est le narrateur lui-même qui commente, lorsque son héros se prend à rêver d'un " triomphe césarien »: «En vain, étourdis par cet air trop vif, les Pâles essayent de l'affadir ${ }^{74}$."

À la longue tirade de César succède une série de courtes répliques où chacun met en avant ses qualités, la première qualité que se reconnaît le jeune homme étant de celles que l'historien Victor Duruy attribuait à... César dans son Histoire des Romains.

Mais pour bien voir comment fut élaboré cet échange entre les deux interlocuteurs, il faut en passer par les notes liminaires, à commencer par trois lignes du feuillet 2 :

je n'ai jamais compté d'une façon absolue que sur moi-même / attentif à saisir les circonstances / excès de passions folles - en apparence calculateurs et impassibles ${ }^{75}$.

Ces quelques notes s'éclairent par la Vie de Napoléon de Stendhal :

"Suivant moi, on ne trouve d'analogue au caractère de Napoléon que parmi les condottieri et les petits princes de l'an 1400 en Italie : les Sforza, les Piccinino, les CastrucioCastracani, etc., etc. Hommes étranges, non point profonds politiques, dans le sens où on l'entend généralement, mais, au contraire, faisant sans cesse de nouveaux projets, à mesure que leur fortune s'élève, attentifs à saisir les circonstances et ne comptant d'une manière absolue que sur eux-mêmes. Âmes héroïques [...] et expliquées seulement en partie par leur contemporain Machiavel. Il n'entrait pas dans le plan de ce grand écrivain [...] de parler des excès de passion folle qui, tout à coup, viennent gâter le talent du Prince. Il passe sous silence et avec grande sagesse, ces bouffées de sensibilité qui, à l'improviste, font oublier toute raison à ces hommes en apparence calculateurs et impassibles ${ }^{76}$."

Lorsque dans ses notes manuscrites Montherlant barre un mot ou un ensemble de mots, cela signifie a priori qu'il les a intégrés dans son œuvre, mais ce qu'on voit ici est doublement intéressant. Ce n'est pas tout à fait le mot de Stendhal (" ne comptant d'une manière absolue que sur eux-mêmes ») que son lecteur a recopié ; il l'a transcrit tel qu'il comptait le mettre dans la bouche du divin Jules : « Je n'ai jamais compté d'une façon absolue que sur moi-même ", avant de se décider pour " Jamais César ne compta d'une façon absolue que sur soi-même ", le fantôme de César ne pouvant parler comme s’il était encore César.

74 Voir les pages 64-65 et 190 de l'éd. originale seulement.

75 Ces notes, alignées l'une sous l'autre, sont précédées d'un mot barré illisible.

76 Op. cit., p. 16-17, Calmann Lévy, 1875. Coïncidence, si c'en est une, ces lignes de Stendhal se retrouveront dans l'essai Montherlant homme de la Renaissance que FaureBiguet, l'ami d'enfance de notre écrivain, publia dans la Revue hebdomadaire du 20 juin 1925 (p. 303), avant d'être escamotées dans la version qui parut quelques mois plus tard chez Plon-Nourrit, où elles auraient dû se trouver à la p. 62 . 
Il faut ensuite aller au feuillet 4, dont la matière provient toute, même si le manuscrit n'en dit rien, de cette Histoire des Romains de Duruy que Montherlant exploita sa vie durant ${ }^{77}$ :

César disait que l'expérience est un grand maître

Jamais il ne cédait à l'emportement Dion [suivi d'un vu entouré]

Ses vices ne troublaient pas sa ferme intelligence, de sorte que l'on put prendre de l'empire sur ses sens et qu'on n'en prit pas sur son esprit : jamais ses plaisirs ne firent tort à ses affaires. Ses victoires mêmes ne lui causèrent pas d'éblouissement.

Il resta le maître de ses soldats comme de lui-même, et seul, avec son génie, dominant du haut de sa fortune le monde étendu à ses pieds, il ne laissa pas monter à son cerveau ces fumées enivrantes de l'orgueil surhumain qui ont plus d'une fois obscurci l'intelligence d'hommes supérieurs

maître de ses passions [précédé d'un vu entouré]

Comme, au milieu de brouillons, il avait seul un dessein arrêté, sa volonté puissante et tranquille faisait tout converger vers un but unique et il l'atteignait

Suétone : (derniers mots) il fut doux et bon.

60.000 .000 d'hommes

mes intérêts se confondaient avec ceux de l'Empire

la tempérance du plus rude soldat

Tout cela vient en fait du tome 3 de l'Histoire des Romains, qu'il suffit d'ouvrir à la page 420 pour y trouver, dans le texte ou dans les notes ${ }^{78}$, ce qui va de "César disait... " à " ... il l'atteignait "; puis à la page 421, où Duruy exalte la bonté de César en renvoyant ses lecteurs à Suétone ${ }^{79}$; puis à la page 422 , où il soutient que "l'assemblée populaire était incapable de gérer les intérêts de soixante millions d'hommes ", et pour finir à la page 10, où il retient " la tempérance du plus rude soldat " parmi les qualités de... Catilina.

Que retrouve-t-on de Duruy dans les répliques de notre page 6 ?

Deux choses sont sûres : " Jamais ses plaisirs ne firent tort à ses affaires " deviendra dans la bouche de l'interlocuteur de César : "Pas une fois le soin de mes plaisirs ne contraria le soin de mon progrès ", et le mot de Dion Cassius : "Jamais il ne cédait à

77 Cette somme fut publiée entre 1879 et 1885 (pour les liens entre Duruy et Montherlant, voir mon article " Henry de Montherlant avec Victor Duruy, Louis Ménard et quelques autres dans "la marmite des penseurs pensants" ", p. 188-197, dans le Bulletin de l'Association Guillaume Budé, 2011, 2).

78 Note 1 : «Il disait que l'expérience est un grand maittre ", pour quoi Duruy se fonde sur un passage du De Bello civili (est rerum omnium magister unus en II, 8) ; note 2 : " "Jamais il ne cédait à l'emportement" (Dion, XXXVIII, 11)».

79 "Il fut doux et bon, lenissimus" (cf. Vie de César, 74, 1). 
l'emportement ", passera dans la réplique où pour la première fois le divin Jules parle de lui-même comme d'un autre : "Jamais César n'agit dans la colère ${ }^{80}$."

Laissons pour l'instant " 60.000.000 d'hommes " (tout en retenant qu'il fut dûment barré) au profit de "la tempérance du plus rude soldat ». Peut-on arguer du fait que le héros du Songe admire autant Catilina que César à cause de son aptitude à "supporter l'excès de la misère " aussi bien que «l'excès de la volupté ${ }^{81}$ ", pour chercher dans cette tempérance l'origine de la réplique "Une amie me nommait "l'inenivrable" " 82 ? Une autre piste s'ouvrira plus loin à nous, qui nous aidera peut-être à trancher, mais une chose au moins est avérée : inenivrable fait partie du lexique d'Alban : "En vérité, j'ai eu une amie qui me nommait l'inenivrable; mais c'est d'un mot plus large encore qu'il faudrait me nommer : l'invulnérable ${ }^{83}$."

[6 $6^{\text {bis-7 }}$ 15-16] Ce n'est évidemment pas dans l'Histoire des Romains qu'il faut chercher le mot que César impute à son interlocuteur : "Tu as dit : "Je ne cherche pas à être heureux..." " On le trouve en revanche très vite, dès les premières pages du Songe, dans ce soupir d'Alban : "La prééminence m'est indispensable ; rien d'elle ne m'attire; il y a simplement qu'une vie sans elle ne m'est pas concevable. Je ne cherche pas à être heureux ${ }^{84}$."

Cela posé, des convergences comme celles qu'on vient de voir ou comme celles qu'on découvrira plus loin ne sont pas seulement le lieu où se rejoignent le dialogue et le roman ; elles peuvent être aussi le lieu - comme il ressortira des raisons que déroule le divin Jules quand il explique à son interlocuteur pourquoi, désormais, il lui semble "davantage pareil aux autres » - où l'auteur joue à se confondre avec ses personnages :

"Tes silences déconcertent : comme tu laisses passer l'une après l'autre toutes les occasions de te mettre en valeur, ceux qui ne te connaissent pas se demandent s'ils ne cachent pas le vide, mais ceux qui te connaissent te mettent à jour, et ils haïssent la suprême marque de dédain que tu leur donnes par ce silence. Quand tu sais et qu'on t'interroge,

80 Détail révélateur, Montherlant avait d'abord écrit : "Je n'ai jamais agi », qui est comme un écho de la note héritée de Stendhal sur le feuillet 2 : "Je n'ai jamais compté d'une façon absolue que sur moi-même. "

81 P. 12 de l'éd. originale (R 10).

82 Inenivrable est rare, tout comme enivrable, mais le premier est dans L'Anti-Justine de Restif de la Bretonne et le second dans L'Eau profonde de Paul Bourget (1902). Pour ce qui est de César, Suétone assure dans un chapitre que Montherlant n’avait pu rater, étant celui d'où il avait retenu que l'homme " mangeait de tout ", qu'il " buvait très peu de vin " (Caes., 53, 1).

83 P. 213 de l'éd. originale seulement. C'est même par le roman qu'on peut déchiffrer le mot " inenivrable " sur le manuscrit.

84 P. 7 (R1 7). Assez vite, Montherlant s'insurgera contre cet acte de foi et on lira dans La Petite Infante de Castille: "Il n'y a qu'un but, qui est d'être heureux » (R1 648). 
tu réponds: "Je ne sais pas". Quand tu viens de lire et qu’on t'interroge, tu réponds: "Je n'ai pas lu”."

En regard de quoi on aura beau jeu de mettre le portrait que Montherlant fera deux ans plus tard de lui-même et qu'on ne connait, sauf erreur, que par un manuscrit, cette fois-ci encore, du fonds Montherlant de Granville ${ }^{85}$ :

"Un cercle de quelques personnes et dedans, un jeune homme silencieux, au visage grave. On discute, il ne prend pas part à la discussion. Alors on l'interroge - "Ce livre ?" - "Je ne l'ai pas lu." - "Cette question politique, qu'en pensez-vous ?” - "Je ne l'ai pas étudiée. Je n'ai encore aucune opinion.” [...]

C'est Henry de Montherlant ${ }^{86}$."

[ $\left.7^{\text {bis_-9 }} 17-19\right]$ On en revient au dialogue pour la question que pose finalement le divin Jules à ce jeune ambitieux qui, selon lui, "n'a plus le droit de n'être qu'un homme ": "Dis-moi donc, oui ou non, si je peux encore te compter parmi les superbes ", en usant pour ce faire d'un mot qui demande un nouveau détour par Le Songe.

Bricoule a fait la rencontre inopinée du Père de Pestour, qui était son confesseur au collège, un " altier religieux " à la " courte barbe romaine " et " de si haute taille sur son cheval énorme qu'il semblait une apparition surnaturelle ». Quelques citations de Matthieu, du genre "Je n'apporte pas la paix, mais l'épée », suffiront à apaiser le jeune homme :

"Père, que tu me fais du bien ! [...] Si Dieu m’a mis parmi les superbes, tu sais bien, toi, que les superbes aiment les petits et méprisent les grands, et que rien n'est plus près de l'anéantissement dans l'humilité que mon orgueil ${ }^{87}$. "

Plutôt qu'à l'injonction païenne : "Souviens-toi de dompter les superbes ${ }^{88}$ ", le contexte (Alban aura pour pénitence d'écrire trois psaumes en latin " à la gloire du Sauveur ») fait penser au Psaume 17: "Tu rabaisseras les yeux des superbes ${ }^{89}$ ", comme si, malgré l'écart du temps, on était déjà dans Le Cardinal d'Espagne, quand la reine Jeanne lance à Cisneros : "Vous vivez parmi les superbes ", et que Cisneros lui répond, sans pour autant la convaincre : «Je n'aime que les humbles ${ }^{90}$. " Le rapprochement peut sembler téméraire, mais c'est un fait que le roman donne des "superbes »

85 Dans le dossier " Notes de guerre " déjà cité.

86 Le manuscrit n'est pas daté, mais l'auteur dit un peu plus loin qu'il a vingt-sept ans. On est donc bien, en principe, deux ans après Jules César.

87 P. 210-211 de l'éd. originale seulement. Il faut savoir que les mots "les superbes " se trouvent tels quels au verso du $\mathrm{f}^{\circ} 2$, parmi d'autres notes qui furent parfois reprises dans le dialogue.

88 C'est l'ombre d'Anchise qui dit à Énée : Tu [...] memento / [...] debellare superbos (VI, 851 et 853).

89 Oculos superborum humiliabis (Ps. 17, 28).

90 En II, III (T 1142-1143). La pièce fut créée le 18 décembre 1960. 
une image qui n'est pas celle du dialogue. À moins d'invoquer ce mot de "charité ", la charité étant vertu chrétienne par excellence, que l'interlocuteur de César va mettre en avant dans sa réponse.

Réponse par ailleurs cinglante, comparer Jules César au " petit garçon " avide de chocolat étant assez inattendu ${ }^{91}$, et si notre "superbe " reconnaît qu'il a "changé, peut-être, avec la vie ", c'est pour mieux incriminer une paix qui a " discrédité l'avenir ».

On s'attendait d'ailleurs à ce qu'il continue sur cette lancée. Or le voilà qui bifurque, faisant l'éloge de la volupté comme de la seule valeur sûre : "Qui voudrait confier à cet avenir autre chose que la volupté ? Elle seule est éternellement assurée. Deux êtres au milieu de l'effondrement total suffisent à maintenir l'espoir de bonheur ", et le faisant avec des mots qui annoncent ceux de Montherlant lui-même dans La déesse Cypris. On sera en 1944, le monde sera en proie aux mêmes tourments, mais le remède n'aura pas changé depuis 1921 :

"Une seule chose empêche l'humanité de désespérer, pendant les époques de désastres: l'être y cherche l'être ; sous les bombes, parmi les cadavres et l'épidémie, il ne pense qu'à cela, et c'est ce qui le maintient debout ${ }^{92}$."

Est tenu pour vain, en revanche, tout ce qui s'apparente au pouvoir : " Mais l'espoir de la puissance est bâti sur les nuées ", ajoute l'interlocuteur de César. C’est une vérité, ou un axiome, que le divin Jules acceptera peut-être plus facilement qu'il ne l'eût fait de son vivant, mais son vis-à-vis ne lui laisse pas le temps de réagir. Le gaillard se lance dans une tirade où il n'est question que de lui-même : "J'ai préféré... Je suis annihilé... Je m'enflerais... », le tout classiquement construit sur une alternative : «Et si j'échoue... Admets enfin que je réussisse..." ".

Abstraction faite de l'étonnante question : "Tuer ? Est-ce que je ne peux pas faire tuer impunément ${ }^{93}$ ? ", deux points sont à souligner dans cette diatribe contre la course aux honneurs.

Il y a de nouveau la question de la paix, criminelle si elle déçoit : "Songe que la tristesse de notre paix est d'avoir été si souvent dupés, songe que c'est par peur de sembler dupes une fois de plus que tant d'honnêtes gens, enragés, se jettent dans l'indélicatesse ", et on sent venir l'appel que lancera, fin 1924, l'auteur du Chant funè-

91 L'anachronisme, en revanche, n'est qu'apparent, puisque le divin Jules connaît aussi bien le $\mathrm{Xx}^{\mathrm{e}}$ siècle après J.-C. que le $\mathrm{I}^{\mathrm{er}}$ siècle avant.

92 E 1573.

93 Moins étonnante qu'il n'y parait si on se rappelle ce passage du Songe : " Mais sa facilité au meurtre n'était pas plus grande qu'hier, dans le Paris nocturne, quand il n'attendait qu'une provocation pour légalement assassiner " (p. 70-71 de l'éd. originale ; R1 46-47). 
bre pour les morts de Verdun : "Il faut faire une paix qui ait la grandeur d'âme de la guerre $^{94}$."

L'autre point, dérivé du premier, est celui du pari hasardeux : "Quel tragique calcul, si, sur mon lit d'agonie, je dois reconnaitre que toute cette partie morte de ma vie a été sacrifiée pour rien! Quel déchirement de m'être crédité sur l'inconnu!», et c'est vers un personnage des Jeunes Filles, M. Charles Dandillot, qu'on est cette fois-ci tenté de se tourner. Quelles que soient les distances entre le dialogue et le roman où se campe Dandillot (l'écart dans le temps, 1921-1936, et un tout autre contexte ${ }^{95}$ ), le déplorable constat que fera cet homme un mois avant sa mort : " La fin des illusions ! J'ai été roulé ", est une mise en garde identique à celle de 1921.

[10-10 bis 20-21] À tout ce qu'il vient d'entendre, César n'a pu opposer d'autre argument que celui de l'orgueil satisfait. Si courte pourtant qu'ait été sa réplique, elle lui vaudra de nouveau une assez roide réponse ("Tu es naïf " et « Je m'amuse de ta perplexité "), son " adversaire " " lui expliquant bientôt pourquoi il est "imprenable».

Il est imprenable parce que tout lui est bon. Il le dira même avec un mot latin : "Quoi que je recherche, si c'est son contraire qui se présente, ave, donc, pour son contraire ", avant de dérouler un véritable catalogue d'infortunes - la ruine, la prison, l'inconfort, l'injure, la maladie, la mort enfin - dans un élan de stoïcisme qui rejoint celui d'Alban dans Le Songe.

Le garçon vient d'apprendre la mort de Prinet, " ami de la première admis$\operatorname{sion}^{97}$ ». Il en est accablé, et pourtant " toutes les fibres de son être étaient tendues, pour nier avec toutes leurs forces que sa douleur fût un mal ${ }^{98}$ ", au point qu' " en cette heure, quand tout était accompli, une parole lui venait aux lèvres, déjà prononcée par

94 P. 125-126 de l'éd. originale, Grasset, 1925 (E 221).

95 Dandillot parle du " fiasco » de son existence dans la mesure où il a " vécu selon certains principes de vie naturelle, qui raisonnablement devaient lui donner longue vie et longue jeunesse », pour mourir à soixante et un ans, qui est «l'âge où tout le monde meurt » (R1 1174).

96 Adversaire est le mot, le divin Jules étant comparé à un lutteur prosterné devant un adversaire insaisissable. Et on note au passage «le cerveau bovin ", qui n'est pas des plus flatteur.

97 Ce n'est pas pour rien qu'on présente ici Prinet comme un « ami de la première admission ". On lit dans Le Songe: "Prinet, cher garçon! Amice primae admissionis! Il est au ...e d'infanterie ; je le rejoindrai " (p. 9 de l'éd. originale, R19), et on pense à la cohors primae admissionis dont parle Sénèque dans le De Clementia (I, 10, 1) pour désigner les premiers favoris du prince, mais c'est en lisant les Mours romaines de Friedlaender que l'auteur du Songe a trouvé ce mot : amicus primae admissionis s'y trouve à la p. 129 et figure au verso du folio 8 dans les notes de Montherlant, preuve, à nouveau, de l'étroite parenté du dialogue et du roman.

98 P. 263 dans l'éd. originale seulement. 
un homme mais qui germait si spontanément de lui-même qu'elle en était comme recréée : "Ô monde, je veux ce que tu veux. Tout ce qui arrive arrive justement" ${ }^{99}$. " Une parole qui est bien sûr de Marc Aurèle ${ }^{100}$, mais que Montherlant reprendra pour lui-même tout au long de sa vie, tant l'" acceptation " stoïcienne lui paraissait s'accorder avec sa nature profonde ${ }^{101}$. Quand l'interlocuteur de César proclame cette espèce d'indifférence au malheur, il est assurément le porte-parole de l'écrivain.

Et tant qu'à débusquer l'auteur derrière ses personnages, arrêtons-nous un instant sur le mot par quoi s'achève la tirade du jeune homme : « (mais tu sais cela, ton monde a su mourir avant le nôtre) ".

Ce n'est qu'une parenthèse, dans la ligne de ce que César a dit plus haut de son peuple : "Déjà il était marqué par la mort ", mais c'est aussi, plus que probablement, un souvenir de ce Quo vadis qui berça l'enfance de Montherlant et dont la trace se retrouve un peu partout dans son œuvre. Dans Le Treizième César en particulier, dans les pages sur la mort de Pétrone : "La phrase essentielle sur le suicide [...] Pétrone l’a dite à Vinicius au cours d'une de leurs conversations [...] : "Celui qui a su vivre doit savoir mourir" 102. " Et si l'on a raison de reconnaître Quo vadis derrière " ton monde a su mourir avant le nôtre ", on aura aussi raison de le reconnaitre, fût-ce a posteriori, derrière " l'inenivrable » de la page 6 du dialogue et de la page 213 du roman, pour ce qu'on lit, cette fois-ci encore, dans Le Treizième César : "Pétrone [...] a les pieds sur terre. Pendant l'"orgie", où tout le monde divague ou roule sous la table, Sienkiewicz nous dit : "Pétrone n'était pas ivre ${ }^{103 " . " ~}$

[11 22] Le divin Jules, jusqu'ici très patient, a commencé de répliquer à son adversaire, lui représentant qu'il n'est pas moins esclave quand il " ne désire pas " que ne le sont ceux-là mêmes qu'il a traités d'esclaves parce qu'ils sont à la merci de leurs besoins.

La réponse fuse : "C'est la volonté des faibles, que l'espérance... Je donne ma vertu pour rien. Je ne puis plus souffrir la pensée d'être payé. » Et pour le coup on n'en finirait pas de dérouler les textes où Montherlant a condamné l'espérance et prôné la

99 P. 265 dans l'éd. originale (R1 166).

100 À y regarder d'un peu près, on voit que Montherlant a fusionné deux, voire trois extraits des Pensées (IV, 23, 1 et X, 21, 1 d'une part ; IV, 10, 1 d'autre part), qu'il cite dans la traduction d'Alexis Pierron parue chez Charpentier en 1843.

101 J'ai parlé d'abondance de l'acceptation montherlantienne dans Montherlant et l'Antiquité, p. 137-158, Bibl. de la Faculté de Philosophie et Lettres de l'université de Liège, fasc. CCL, "Les Belles Lettres", 1987.

102 Le Treizième César, p. 174. Il faut aller à la fin du chap. VII de la Deuxième partie de Quo vadis, où Pétrone dit plus exactement, pour opposer les Romains aux chrétiens : « Nous saurons vivre et nous saurons mourir."

103 Ibid., p. 167 en note. Pour Quo vadis, on ira cette fois-ci au chap. VII de la Première partie. 
vertu qui se satisfait d'elle-même. "La vertu n'est vertu que désintéressée. [...] Tout acte de vertu qu'on fera, on le fera par peur de ton enfer, et dans ton ciel immoral, il n'y aura que les égoïstes et les lâches ", lançait déjà le dieu Pan à Jésus dans un " conte antique " de $1912^{104}$. En 1929, c'est l'auteur de Trois Jours au Montserrat qui traitera l'espérance de " maladie honteuse de l'âme " avec des mots qui nous sont familiers : "Comme les Anciens ont vu juste, qui ont considéré l'espérance comme un daemon funeste aux hommes! Cependant, ce daemon, un jour vint où les caractères affaiblis ne purent plus s'en passer ${ }^{105}$ ", et la préface de 1933 de La Relève du matin parlera avec dédain d'un «Dieu rétributeur ${ }^{106}$ ".

L'indifférence où vit celui qui n'attend rien que de lui-même a, semble-t-il, pour effet de le dépouiller de tout ce qui l'encombre ou l'entrave. L'auteur de La Petite Infante de Castille dira un jour, pour définir le parfait bonheur qu'il avait connu, ou failli connaître, en 1928 dans " l'île de la Félicité " : " Je n'avais plus le temps d'espérer, plus de me souvenir ${ }^{107}$ ", qui recouvre d'assez près ce mot du dialogue : "Je n'ai plus conscience de ma vie que par cela qui se détache d'elle - des affections, des aversions, des espoirs, des souvenirs. " Avec cette nuance que le Montherlant de 1921 est l'homme du Neuilly familial, où il vit depuis 1907, tandis que le Montherlant de 1928 est celui qui, en janvier 1925, avait "gagné le large » avec l'intention ferme de "réaliser la féerie " et de "se désolidariser 108 ». Tout ce qu'on peut dire des propos que tient l'interlocuteur de César, c'est qu'ils sont diantrement prémonitoires, même si la vision que suscite en lui ce détachement à nul autre pareil est avant tout celle d'un meurtre aux relents de parricide.

Une vision qui nous ramènera (avec, pour que nul n'en ignore, un appel de note renvoyant à Plutarque ${ }^{109}$ ) vers cette Rome ancienne que les deux interlocuteurs ont un peu négligée dans le feu de la discussion :

"Alors je te revois lorsque sous les coups d'épée "traînant ton corps de côté et d'autre en poussant de grands cris, tel qu'une bête féroce assaillie par les chasseurs" (misérable dieu, tu avais donc bien peur de mourir !), tu vis Brutus qui venait sur toi. Enfin tu fis un geste d'homme, tu te couvris la tête de ta robe, et cessas de te défendre. Voilà pour moi le geste de ta vie." "

104 Pour ce conte intitulé Le dieu Pan, voir de nouveau "Henry de Montherlant "entre deux mondes" : la leçon des manuscrits (I) », p. 55-56, dans Anabases 16, p. 49-83.

105 E 400. Revoilà notamment le démon de la page 1.

106 E 14. L'auteur du Treizième César aura changé d'opinion sur cette question de l'espérance, sans préciser s'il englobait alors dans l'espérance celle d'une rétribution post mortem: « [...] dans mes livres j'ai craché plus d'une fois sur l'espérance, par un sentiment de gloire qui voulait défier la réalité. Crachats que j'essuie aujourd'hui » (p. 173).

107 R1 638. L'île de la Félicité n'est autre que Triana, le quartier gitan de Séville.

108 Tout cela est expliqué dans l'Avant-propos de Service inutile (E 572).

109 Que Montherlant cite, semble-t-il dans la traduction d'Alexis Pierron, elle-même proche de celle de l'abbé Ricard (Vie de César, 66, 10-12). 
Deux choses retiendront notre attention. Ce sera d'abord la parenthèse, moins pour son " misérable " un peu condescendant que pour le départ qu'elle fait entre l'homme qui se débat quand une issue lui paraît encore possible et celui qui renonce quand la trahison du « fils » devient évidente; ce sera ensuite et surtout le paradoxe que recouvre : "Voilà pour moi le geste de ta vie ", mais ce paradoxe perd de son étrangeté pour qui considère l'œuvre à venir de Montherlant.

Dans La grande Tentation, l'essai de 1929 où il fut si sévère pour le Dialogue de Sylla et d'Eucrate, Montherlant qualifiera César de "renonciateur malgré lui ", et de "magnifique cri de frousse " le mot qu'on lui impute volontiers : "Plutôt mourir une fois, que trembler toujours ${ }^{110}$. " Dans La Mort de Pompée en 1958, il opposera le silence de Pompée quand on le poignarde aux «hurlements " que pousse César dans la même circonstance, mais en soulignant que l'un et l'autre se couvrent le visage de leur robe dans " le geste classique des Romains que l'on tue » et qui par là "se mettent eux-mêmes au-delà 111 ». Dans ses derniers carnets, se souvenant peut-être plus de Suétone que de Plutarque (selon Suétone, César n’aurait poussé qu’un gémissement au premier coup reçu), il ne retiendra que "le silence final des Romains que l'on tue ": "César, Pompée se couvrent le visage d'un pan de leur manteau, se retranchent. "Je suis au-delä"112. " Tout ce que Montherlant dira, au fil des ans, de la fin de César dérive en somme, d'une façon ou d'une autre, du dialogue de 1921.

[12 23] Le divin Jules ne voit pas les choses du même œil que son adversaire et il le lui dit avec les mots que lui prête Plutarque, mais pour les commenter comme seul un fantôme peut le faire, ou alors un homme revenu de tout :

"Le geste de ma vie est celui que j'eus quand, briguant la place de grand pontife, je quittai ma mère le jour de l'élection avec cette parole : "Ce soir tu me verras grand-pontife ou banni." J'ai dit cela. Tant j'avais faim de cette ombre ${ }^{113}$ !»

La suite est assez réjouissante. Traité plus haut de "petit garçon ", notre revenant n'y va pas de main morte, déniant à son interlocuteur une divinité sans commune mesure avec celle qu' "un peuple de soixante millions d'hommes » (revoilà Duruy !) lui avait de son vivant octroyée " par la voix du sénat »:

110 E 620. Tel qu'on le lit ici, c'est à nouveau chez Boissier qu'il faut chercher ce mot, dans les toutes dernières pages de Cicéron et ses amis (voir mon article "Les douze ou treize Césars de Henry de Montherlant ", p. 285 in Présence de Suétone, Actes du colloque tenu à Clermont-Ferrand en novembre 2004, ed. Rémy Poignault, Centre de Recherches A. Piganiol, 2009).

111 T 1336.

112 Garder tour en composant tout, p. 375, parmi les notes des "trois dernières années".

113 Rapportée par Plutarque (7, 3), la parole de César à sa mère l'est aussi par Suétone (Caes., $13,1)$, mais la formulation n'est pas la même. 
"Tu t'es fait crevette en devenant dieu... Mais dieu, qui t’a nommé dieu ? Toi-même tu t'es nommé dieu !... Ô impuissant ! Ô crevette insensible ! Ô Grec perfide qui prétends faire mettre un diadème à ta lâcheté ${ }^{114}$ ! »

[14-19 24-30 ${ }^{115}$ Piqué au vif, notre crustacé se lance dans un éloge nietzschéen de la force qui l'oblige quasiment à passer par le latin virtus ${ }^{116}$, avant de se définir luimême en face des " objets extérieurs".

L'idée maîtresse de son exposé étant celle que Bricoule développe dans Le Songe quand son ami Prinet lui demande s'il ferait, le cas échéant, "le petit pas qui sépare les promesses, les intentions, les paroles, de l'acte qui est vraiment la pleine mesure du sacrifice ", le mieux sera de mettre en parallèle le texte de Jules César (des passages de la page 15 et de la page 19) et celui du Songe:

Dans l'Iliade, Diomède se rue sur Énée bien qu'il sache qu'Apollon rend Énée invulnérable. Hector prédit la ruine de sa patrie, la captivité de sa femme avant de retourner se battre comme s'il croyait en la victoire. Quand le cheval prophétique annonce à Achille sa mort prochaine : " Je le sais bien ", répond-il, mais au lieu de se croiser les bras et d'attendre, il se rejette et tue encore d'autres hommes dans la bataille. Ainsi je vis, sachant la vanité des choses, mais agissant comme si j'en étais dupe, et jouant à faire l'homme dans la mesure où je gagne à ce jeu.
Je le ferai, s'il le faut [...]. J'ignore l'utilité de mon sacrifice, et dans le fond je crois que je me sacrifie à quelque chose qui n'est rien, qui est une de ces nuées que je hais. Croyant mon sacrifice inutile, et peut-être insensé, sans témoin, sans désir, renonçant à la vie et à la chère odeur des êtres, je me précipite dans l'indifférence de l'avenir pour la seule fierté d'avoir été si libre. Dans l'Iliade, Diomède se rue sur Énée bien qu'il sache qu'Apollon rende Énée invulnérable. Hector prédit la ruine de sa patrie, la captivité de sa femme avant de retourner se battre comme s'il croyait en la victoire. Quand le

114 "Crevette " peut étonner, mais pas plus que " petit ver de terre " dans la bouche de Sganarelle s'adressant fictivement à son maître (Dom Juan, I, II), et "Grec perfide " est dans le ton de Juvénal, pour qui les Grecs sont des filous, voire du Montesquieu des Considérations quand il relève, citation à l'appui, que Polybe "dit que, de son temps, les serments ne pouvaient donner de la confiance pour un Grec» (op. cit., ch. X).

115 Rappelons qu'il n'y a pas de page 13 ; il y a, en revanche, une page $14^{\text {bis }}$.

116 Montherlant avait découvert Nietzsche en 1916 (voir FAURE-BIGUET, Les Enfances..., p. 168,170 et 171$)$. 
Je donne aux hommes un témoignage d'amour au-delà duquel il est peu de chose, étant prêt à donner à leurs croyances et à leurs soins, alors que je n'y ai pas part, cette pleine et suprême mesure du sacrifice que c'est de sacrifier sa vie. [...] Renonçant à la vie et à mes fous plaisirs effrénés, sans témoins, sans regret, sans espérance, sans croire à rien qu'à l'inutilité de mon sacrifice je me précipite dans l'indifférence de l'avenir, pour rien d'autre que la perfection d'un acte pur. Oui, perdons-les l'une dans l'autre, mon indifférence et celle de l'avenir! Après avoir feint d'avoir de l'ambition et je n'en avais pas, feint de souffrir et je n'ai jamais souffert, feint d'attendre et je n'attendais rien, je meurs en feignant de croire que ma mort sert, mais persuadé qu'elle ne sert pas, et proclamant que tout est juste. cheval prophétique annonce à Achille sa mort prochaine : "Je le sais bien ", répond le héros, mais au lieu de se croiser les bras et de l'attendre, il se rejette et tue encore d'autres hommes dans la bataille. Ainsi ai-je vécu, sachant la vanité des choses, mais agissant comme si j’en étais dupe, et jouant à faire l'homme pour n'être pas rejeté comme dieu. Oui, perdons-les l'une dans l'autre, mon indifférence et celle de l'avenir! Après avoir feint d'avoir de l'ambition et je n'en avais pas, feint de craindre la mort et je ne la craignais pas, feint de souffrir et je n'ai jamais souffert, feint d'attendre et je n'attendais rien, je meurs en feignant de croire que ma mort sert, mais persuadé qu'elle ne sert pas, et proclamant que tout est juste ${ }^{117}$.

Sans doute les discours de Bricoule et de ce double qui est aussi son aîné (car l'action du Songe se situe en 1918, alors que le dialogue est censé se tenir après la guerre) divergent-ils sur un point de détail : l'un dit qu'il a vécu en « jouant à faire l'homme pour n'être pas rejeté comme dieu ${ }^{118}$ ", l'autre qu'il vit en " jouant à faire l'homme dans la mesure où [il] gagne à ce jeu ", mais ce n'est en effet qu'un détail, l'essentiel tenant à cette éthique du jeu que l'aîné va retrouver et développer dans le sport comme Montherlant - nouvel amalgame! - s'occupait à le faire durant ces années 20-21. De là vient d'ailleurs que du jeu on passera naturellement à la feinte : «Tu me verras bondir sous l'outrage et punir l'insulteur, mais dans la réalité l'outrage ne m'a pas blessé ${ }^{119}$ »; puis au mépris : «Cela m'est égal »; puis au masque de l'acteur tragique dissimulant un sourire. Disons-le tout net, il y aurait ici matière à une longue dissertation sur la notion de jeu telle que la développera l'auteur des Olympiques en 1924 et celui de l'Allocution

117 Voir p. 171-172 de l'éd. originale (R1 110-111). Christian Lançon, qui me fit découvrir Jules César, l'a de même noté. Pour l'Iliade, voir Montherlant et l'Antiquité, p. 39.

118 Ce qui pourrait éclairer, tant les deux œuvres parfois s'interpénètrent, l'apostrophe de César dans le dialogue : "Mais toi, qui t’a nommé dieu ? Toi-même tu t'es nommé dieu !...»"

119 Quand l'ombre lui a dit à la page 7 : "Tu es davantage pareil aux autres, aujourd'hui », le jeune homme a déjà répondu : "Indifférentes me sont toutes injures et la tienne, semblables à l'eau sur un torse frotté d'huile. » 
à des étudiants allemands en 1929, mais on s'en gardera bien, Patrick Brunel ayant fait, il n'y a pas si longtemps, le tour complet de la question ${ }^{120}$.

Cela étant, le jeune homme, ou celui qui le fait parler, n'ignore pas qu'il aura le plus grand mal à concilier le mépris des choses humaines avec la volonté d'en tirer parti, et l'avertissement que lui lance César : " Je tremble qu'un jour tu ne regrettes d'avoir voulu être à la fois le héros et le sage, garder la sérénité et garder les passions. Prends garde à ces conciliations! ", mène tout droit à ce qu'écrira vingt ans plus tard, juste après l'armistice, l'auteur du Solstice de juin :

"Que voulons-nous en fin de compte? Un intelligent, et qui ait du sang. Son sang le pousse au combat ; son intelligence postule l'incroyance. Le combat sans la foi, c'est la formule à laquelle nous aboutissons forcément, si nous voulons maintenir la seule idée de l'homme qui soit acceptable : celle où il est à la fois le héros et le sage ${ }^{121}$. »

L'interlocuteur de César est précisément de ces " intelligents qui ont du sang ». Ravalé au niveau du crustacé, il avait rugi : "J'ai mon sang, Jules César, mon sombre sang chargé de naphte, et pourtant pur. " C'est cela même qui le pousse, après avoir vanté " la perfection d'un acte pur ", à démonter le paradoxe : "Cette mort que j'ai voulue vaine ne sera pas vaine. "

[20-21 31-32] Pour parvenir à ses fins, le jeune homme va parler la langue qui sera celle de Montherlant lorsqu'il publiera dans la Revue hebdomadaire du 25 juin 1921 un long article en faveur de cette CEuvre de l'Ossuaire de Douaumont dont il était le Secrétaire général.

L'article s'intitule Le Reliquaire de la vie meilleure et l'autel de la Sainte Force et sera en partie intégré, fin 1924, dans le Chant funèbre pour les morts de Verdun. Voici donc en parallèle le texte de Jules César - à l'état brut - et celui du Reliquaire ${ }^{122}$ :

120 Voir "Henry de Montherlant : "esprit de légèreté" et esthétique du "double jeu" ", p. 381-406, dans La Pensée du paradoxe : approches du romantisme. Hommage à Michel Crouset, PUPS, 2006.

121 E 921. Le Caton de La Guerre civile, en 1965, sera le parfait porte-parole du " combat sans la foi " (T 1361).

122 Qu'on trouvera à la p. 480 de la Revue hebdomadaire. 
L'acte pur que nous avons lancé dans l'obscurité itt. de l'histoire, allume des constellations qui ne sont pas pour nous. Le patrimoine idéal offert à chacun de nous par le néant est formé de millions d'actes qui relativement aे leurs buts dans leur temps n'ont servi à rien. Tu as augmenté ton Empire, mais tes successeurs ont tout perdu. Il n'est rien de ce que tu as construit, avec tes prudences, tes sueurs, tes calculs, l'effort et la réussite de toute ta vie, qu'il n'ait été dans le pouvoir du plus incapable de tes successeurs de détruire, et qu'il n'ait en effet détruit en une heure ou en une seconde par imbécillité stupidité ou par fantaisie. Tu as travaillé en pleine caducité, et davantage encore que les autres, peut-être, puisqu'il est d'expérience qu'un génie plus médiocre réussisse où un génie plus grand a échoué, et que tout ce qui subsiste un peu a été fait par des hommes de second choix. Et pourtant, c'est de cette somme de francs échecs et de victoires inutiles qu'est fait le don que tu as fait au monde. Nous autres, nos gains de la guerre seront-ils maintenus ? On vient nous dire : " $\#$. Au prochain coup Verdun sera pris ", ou : "Ils sont morts pour ceci et cela... mais ceci et cela ne sont pas obtentus n'a pas été obtenu à cause de la mauvaise paix, de l'incurie etc. " Mais qu'est-ce que cela fait ? Chacun de leurs actes est entré dans le domaine où rien ne peut rien contre lui. Que l'océan recouvre la France, s'il épargne un seul homme qui pense et qui se souvient, le sacrifice de dix sept cent mille morts n'aura pas été inutile.

Toile de Pénélope [p. 21 dans la marge]
Par un demi-siècle de tension, de calculs, la plus excédante industrie, Auguste fonde l'Empire ; par une heure ou une seconde d'imbécillité ou de lubie, son successeur détruit tout l'Empire ; et cependant, considérant cette ruine, nous ne disons pas qu'Auguste a existé en vain. L'héritage sans prix du passé dont nous sommes les bénéficiaires est fait de myriades d'actes qui, relativement à leur but, ont été des échecs. Nous travaillons sur une toile de Pénélope où l'ouvrage des mains du jour est défait par les mains de la nuit, et plus sûrement peut-être les plus grands, puisqu'il semble d'expérience qu'un génie plus médiocre réussisse où un génie plus grand a échoué, et qu'en général ce qui subsiste un peu a été fait par des hommes de second choix ; mais un travail que nous ne connaissions ni ne voulions est fait, et nous construisons un bien à coups de victoires inefficaces et par les erreurs mêmes qui nous ont le mieux éreinté. Un philosophe m'oppose : "Qui vous dit que, dans dix siècles, l'arrêt des Allemands devant Verdun ne sera pas jugé un manque à gagner pour le monde ? " Un pyrrhonien : «Que deviendront vos brillants témoignages, si à la prochaine guerre Verdun est pris ? " [...] Je réponds : "Qu' est-ce que ça fait ?" J'ai vu [...] la vertu de l'homme. Peu m'importe si elle a atteint ses buts; il me suffit qu'elle ait existé. [...] Tirez où vous voulez nos dix-sept cent mille morts pour me faire voir comme ils sont stériles; il existe un terrain où ils répandent lumière et force et sur cette position inexpugnable je puis les ramener quand je veux, hors l'atteinte de notre pauvre pouvoir de défaire. Vienne le déluge : ils sont dans l'arche. 
C'est à l'évidence le Secrétaire général de l'CEuvre de l'Ossuaire qui s'est exprimé dans Jules César comme il le fera dans Le Reliquaire. On dit bien " comme il le fera", parce qu'on a deux raisons au moins, laisserait-on de côté le fait qu'Auguste a pris la place de César, pour situer la version de la Revue hebdomadaire après l'autre. Première raison, le passage souligné de la page 20 n'a pu l'être que par l'auteur du Reliquaire préparant son article pour la revue et choisissant par la même occasion d'en revenir à cet "imbécillité " auquel il avait précédemment renoncé au profit de "stupidité ». Seconde raison, la note marginale de la page 21 : «Toile de Pénélope », sera développée dans le Reliquaire ${ }^{123}$. De quoi régler, soit dit en passant, la question de la date de Jules César: après la mi-janvier, à cause de trois supports bien précis; après le 21 avril, si par miracle il fallait prendre à la lettre l'affirmation du début : " Il y a eu hier un quart de siècle que j'existe ", et bien avant le 21 juin 1921, si l'on tient compte des délais entre le dépôt d'un article et sa parution.

[21-24 32-35] La célébration de "l'acte pur ${ }^{124}$ " a comme attendri les deux interlocuteurs. "Cessons de nous disputer, mon César ", dit le jeune homme. " Nous n'avons pas vraiment disputé : la grandeur de mon âme me rend apte à tout comprendre ", répond le fantôme avec un mot qu'il affectionne, l'ayant déjà cité pour lui-même et pour le peuple romain ${ }^{125}$, que Montherlant affectionnait et qui dérive de celui que Montesquieu a mis dans la bouche de son Lysimaque parlant d'Alexandre : " Ce moment fut celui du retour de sa grande âme. " "Cette phrase a été vivante et émouvante en moi pendant cinquante ans ", dira l'auteur de La Guerre civile, en précisant qu'elle concrétisait à ses yeux "le mouvement qui déclenche chez ces hommes [les hommes de pouvoir], alors qu'ils sont plongés dans leurs horreurs, une réaction imprévue de noblesse et de générosité ", et en rangeant César parmi ceux qui, " peut-être parfois ", en firent la démonstration ${ }^{126}$. Montesquieu va d'ailleurs resurgir avec cette

123 La version du Chant funèbre (p. 72-73 de l'éd. originale, E 201-202) est encore différente. Charlemagne et Napoléon viendront par exemple s'ajouter à Auguste. En revanche, le mot caducité qui était dans Jules César ("Tu as travaillé en pleine caducité ") mais avait disparu du Reliquaire, refait surface avec le Chant funèbre: "Notre entreprise est sujette à tous les caprices de la caducité ", et quand on sait comment travaille Montherlant, on n'hésite pas un seul instant à y reconnaître une exhumation du "caducité " de Jules César.

124 On a cité "Toile de Pénélope " parmi les notes marginales de la p. 20, mais c'est un ensemble de notes marginales qu'il faudrait citer : une note à la p. 19 "Celui qui sauvera sa vie la perdra. Matth. X, 39 », et trois autres notes à la p. $20:$ "Il faut tout sacrifier pour tout avoir "; "Trouver la route de l'avenir en se trompant de chemin et en cherchant à atteindre les mirages irréels de leur imagination »; "un mot ill. les songes que tu as mis au monde, voilà les monuments ». Ce n'est sans doute pas un hasard si Matthieu est l'Évangéliste que le Père de Pestour cite à trois reprises dans la version originale du Songe.

125 Voir p. 3 et 5 du dialogue.

126 Dans la Postface de la pièce, datée de mai 1964 (T 1311). 
autre réplique du divin Jules : «Pour que la nature rompe au profit de l'un l'égalité qu'il y a parmi les hommes, il en coûte trop à tous les autres ", où Montherlant combine une note du feuillet 2 : "Rompre à mon profit l'égalité entre les hommes ", et une note du feuillet 5 dans laquelle on reconnaîtra une parole d'Eucrate à Sylla : « Il est juste que la société te haïsse, pour ce qu'elle souffre de toi. "Pour qu'un homme soit au-dessus de l'humanité, il en coûte trop cher à tous les autres". "

Dès cet instant, le jeune homme n'aura plus pour l'ombre que des mots de reconnaissance et d'admiration, des mots qui seront assumés par Montherlant lui-même dans les mois ou les années à venir. "Je me meurs à côté de ce qui n'est pas grand " annonce très précisément l'apologie de la grandeur qu'on aura dans l'hommage à Barrès du 5 décembre 1923 :

"En septembre 1917, soldat, écrivant à Barrès, que je ne connaissais pas, je lui parlais de quelqu'un qui "avait eu les larmes aux yeux en se représentant seulement sa mort", à lui, Barrès. [...] Or, la voici, cette mort, et, fidèles au rendez-vous, les voici, ces irrésistibles larmes [...]. Et sur quoi ? Sur la grandeur. Comme sur la mort de Don Quichotte quand j'avais dix ans. Comme sur Longwood quand j'en avais quinze. Comme sur le cercueil de César, transporté au-dessus de la foule, dans un film de cinéma, quand j'en avais vingt, casqué, tueur d'hommes ${ }^{127}$."

Et le plus étonnant n'est pas dans le texte de 1923, il est dans ces quelques lignes du dossier liminaire de Jules César dont sortira la page de 1923 :

Quand j'ai senti les larmes me travailler les yeux à la mort de Jules César

Ce corps immobile porté très haut sur les épaules, oh si immobile, avec sa tête pendant en arrière

Lui qui avait tant fait : tant de choses, tant de plans, tant de machinations, tant d'agitation, et le voilà

Ainsi une nuit j'ai pleuré de vraies larmes sur Barrès, en l'imaginant sur son lit de mort, et tel autre écrivain si j’apprenais soudain sa mort, je suis sûr que je pleurerais devant le monde, et pourtant je ne sais rien de lui

Ainsi sur l'agonie de Napoléon - parce que ce sont des héros ${ }^{128}$.

Quant à l'ultime protestation du dévot : "Dans la guerre j'ai lutté contre la pensée de ma mort, jusqu'au jour où l'idée m'est venue que je te retrouverais là-bas ; dès ce jour-là, j'ai accepté ", elle est dans la déclaration que Montherlant fera en 1922 à Pierre Varillon et Henri Rambaud, lorsqu'ils enquêteront « sur les maîtres de la jeune littérature " :

127 Dans Barrès commence son rôle d'outre-tombe, qui parut d'abord dans Les Nouvelles littéraires du 8 décembre avant d'être repris en 1927 dans Aux Fontaines du désir (E 268-269).

128 Ces notes proviennent du feuillet 6. 
"L'espérance de pouvoir retrouver Jules César dans une autre vie m'a aidé à supporter tel bombardement ; si c'était une affectation que ceci, elle serait ridicule et misérable ; pour risquer que ce soit soupçonné d'en être une, il faut être soutenu par un puissant amour $^{129}$."

\section{Une œuvre nécessaire?}

On a réglé plus haut la question de savoir quand fut écrit Jules César : mettons au printemps 1921. On a vu aussi, à maintes reprises, comme il est proche du Songe, et singulièrement de la version originale du Songe. Le roman, dont la composition s'est étalée sur trois ans au moins, fut conçu bien avant le dialogue, mais c'est un fait que les deux œuvres firent ensemble un bout de chemin ${ }^{130}$. En veut-on une preuve de plus, on l'aura avec ce court extrait d'un autre manuscrit du Musée Richard Anacréon de Granville :

visage éclairé par la souffrance-

dans ma grande âme

laraire - dédicatoire aux dieux

un désaccord et un trouble-sur-ctans nos opinions sur les bienset les maux

les nuits appartiennent aux morts

les tourments qui exercèrent les songes qu'ils ont mis au monde, voilà les monuments ils ne se sont pas tant travaillés pour rien.

Mais non, tu t'en vas...

long comme $<$ tout $>$... un petit brin [en ajout]

Pauvre corps, qu'a-t-on fait de vous

détenu par vous

Quand on essaie de démêler cet écheveau, qu’y voit-on?

On voit d'abord que "visage éelairé par la souffrance " est repris dans Le Songe, quand le narrateur s'apitoie sur des mourants dont « le visage était éclairé par [la] souffrance comme par une lampe ${ }^{131}$ ».

129 Enquête sur les maîtres de la jeune littérature, op. cit., p. 111. L'ouvrage est de 1923, mais Montherlant y est présenté comme celui qui " n'a encore écrit que La Relève du matin"; on n'est donc pas loin de Jules César. Parmi les mots des Anciens qui l'ont le plus marqué, Montherlant cite la réponse de César à Metellus : "Le temps des armes n'est pas celui des lois. " Et les deux mots du lexique gréco-latin qui le touchent le plus sont kalos et le virtus qu'on a lu dans Jules César (ibid., p. 112).

130 Faut-il rappeler que telle note du dossier liminaire de Jules César (amicus primae admissionis au verso du folio 8) n'apparaît que dans le roman ?

131 P. 220 de l'éd. originale (R1 135). 
On reconnait ensuite des mots et des formules de Jules César. Certains nous sont devenus familiers : "dans ma grande âme ", par exemple, qu'il n'est plus nécessaire de commenter ; "Mais non, tu t'en vas" au moment de la séparation et, plus que tout, l'avertissement d'Hésiode tel qu'il figure travesti au début du dialogue : "les nuits appartiennent aux morts ", cependant que d'autres, parmi ces mots, restèrent en rade, soit dans les notes soit en marge du texte. C'est ainsi que " un désaceord et un trouble tans nos opinions sur les biens et les maux ", barré dans le manuscrit de Granville, rejoint une note du feuillet 3 : " un désaccord et un trouble dans nos opinions s. les biens et s. les maux ", qui, n'étant pas dans le texte, n'a pas été barrée ${ }^{132}$, tandis que "les tourments qui exercèrent les songes qu'ils ont mis au monde, voilà les monuments " aboutissait à une note en marge de la page 20 : «Les songes que tu as mis au monde, voilà les monuments. "

Et ce n'est pas tout. Non seulement "Pature eorps, qu'a-t-on fait de vours" annonce un vers du poème liminaire du Chant funèbre de 1924 : «Pauvre corps, qu'at-on fait de toi 133 ! », mais une note au recto du manuscrit de Granville : «Bien au-dełà de nos pauvres pouvoirs de modiffer et de fixer ${ }^{134}$ ", invite à retourner aux lignes du Reliquaire qu'on a lues plus haut sur cette " position inexpugnable " d'où l'auteur se fait fort de ramener à son gré, " hors l'atteinte de notre pauvre pouvoir de défaire ", les dix-sept cent mille morts de Verdun.

Cela fait sans doute beaucoup de minuties, mais vivent les minuties quand elles nous permettent d'explorer les confins d'où l'écrivain tire ses mots. Or nul ne fut plus habile que Montherlant à tirer de notes parfaitement disparates, et parfois très anciennes, de merveilleuses combinaisons. Lui-même parlait sans détour de " cuisine littéraire " et de sa "propension inavouable à l'arrangement ${ }^{135}$ ", et si l'on a parfois l'impression qu'il va "à sauts et à gambades ", à l'instar de ce Montaigne qu'il avait découvert à seize ans et qu'il a si volontiers cité ${ }^{136}$, c'est parce qu'on oublie qu'il affectionne le mélange des genres (une tirade aux allures d'essai ne le gêne donc pas) et qu'il n'est pas non plus adversaire de la digression : " Je m'esgare, mais plustost par licence que par mesgarde », disait tout justement Montaigne pour se dédouaner d'une « farcis-

132 Le mot est d'Épictète (Entretiens, II, 21, 4) ; il suit, sur ce feuillet 3, un autre mot d'Épictète : "Tout en moi est irrévocable ehrez mơ et tout y est sûr " (II, 8, 26), qui est lui-même issu de l'Iliade (I, 526-527).

133 E 179.

134 Une note barrée au crayon quand d'autres sur cette même page ou au verso sont barrées à l'encre ou au crayon rouge, indices d'utilisations réparties dans le temps.

135 Dans Les Souleveurs de pierre, un article publié dans Le Figaro du 27 janvier 1933 où il fait l'éloge de l'helléniste Victor Bérard et du médiéviste Joseph Bédier.

136 C'est en juillet 1911, en même temps que Pascal, Horace et l'Imitation de Jésus-Christ, que Montherlant lit Montaigne (voir FAURE-BIGUET, Les Enfances de Montherlant, p. 77 ; voir aussi Montherlant et l'Antiquité, passim). 
seure $^{137}$ ». Il serait de toute façon malvenu de prendre le Jules César qu'on vient de lire pour autre chose qu'un brouillon ; le soin que Montherlant réservait à ses textes, jusque dans la correction des épreuves ${ }^{138}$, donne à penser qu'entre la version qui nous en est parvenue et celle qu'il aurait publiée, il y aurait eu pas mal de changements ${ }^{139}$.

Plus délicate sera la question qu'on ne peut esquiver ${ }^{140}$, la question de savoir jusqu'à quel point Montherlant s'est lui-même dépeint dans ce dialogue où Rome n'est pas toujours au premier plan. Le lecteur a certes eu droit à quelques traits qui renvoient au monde ancien : la bulle d'or (p. 6), l'avertissement de l'esclave au triomphateur (p. $7^{\text {bis }}$ ), l'Érèbe (p. 9), le rameau d'olivier à la naissance d'un fils (p. 15); il a eu droit, avec Friedlaender, à un exposé en bonne et due forme sur les " mœurs romaines ", et il a eu son content d'Homère et plus encore de Plutarque ${ }^{141}$, mais il a aussi trouvé dans Jules César pas mal de traits et quelques « actes de foi » que Montherlant revendiquera pour lui-même : comment en user avec le monde, l'éloge de la volupté, la soumission au destin, la vie vécue comme un jeu, la célébration de la grandeur, l'apologie de l'acte pur, l'hommage à ceux de Verdun. Difficile en de pareils cas de ne pas reconnaître l'écrivain derrière son personnage. Chacun jugera si l'on a trop souvent cédé à la tentation de l'amalgame.

Une dernière question, elle aussi inévitable : pourquoi Jules César est-il resté dans un tiroir ? Sans doute parce que l'auteur eut bientôt le sentiment qu'il n'aurait rien gagné à publier, en 1921 ou plus tard, une œuvre qui faisait un peu double emploi

137 Essais, III, IX. Le mélange des genres et la digression dans Les Olympiques de 1924 et dans l'œuvre qui leur fit écho en 1972, Mais aimons-nous ceux que nous aimons?, ont fait l'objet d'une éclairante communication de Romain Lancrey-Javal lors du colloque Montherlant de novembre 2012.

138 On lit ceci dans un carnet de mai 1937 : «Les traits ajoutés sur épreuve (d'imprimerie) sont ceux auxquels l'auteur tient le plus " (E 1216).

139 Tel qu'il est, le texte porte la trace déjà de nombreuses corrections. Il suffit d'avoir le manuscrit sous les yeux (les pages $7^{\text {bis }}$ et 8 , par exemple, avec tous leurs béquets) pour s'en rendre compte. La difficulté majeure consiste à distinguer parfois les changements d'interlocuteur. Fort heureusement, l'auteur s'en est tenu le plus souvent à un code très rigoureux : un tiret marque un changement d'interlocuteur et des guillemets fermants marquent le passage d'un alinéa à l'autre à l'intérieur d'une réplique.

140 Aurait-on à l'esprit la mise en garde de Patrick Brunel : « ... ne pas attribuer inconsidérément à l'auteur les pensées et les propos de tel ou tel protagoniste censé être son double ou son porte-parole ", dans l'article déjà cité : "Henry de Montherlant : "esprit de légèreté" et esthétique du "double jeu" ", p. 391.

141 Bricoule a du reste un Plutarque dans sa musette et le soldat Montherlant en avait un lui aussi, qu'il s'était fait envoyer par sa grand-mère (voir Montherlant et l'Antiquité, p. 38-42). Aux traces de Plutarque qu'on a trouvées dans le texte même, il faut ajouter ces lignes, barrées, au verso de la page 15: « Pour César / On ne sait pas assez que j’ai longtemps [un mot sauté qui pourrait être « tenu »] dans ma main le billet qui m'annonçait de prendre garde ", qui sont un souvenir de Plutarque (Vie de César, 65, 3) ou de Suétone (Caes., 81, 8), bien moins sollicité que Plutarque, il est vrai, dans le dialogue. 
avec Le Songe tout en empiétant sur Le Reliquaire. Tel qu'il est cependant, ce dialogue aux allures d'autoportrait reste un jalon digne d'intérêt, à côté du roman et de l'essai, sur la route menant au Chant funèbre pour les morts de Verdun. S'il n'a pas fait la guerre qu'il avait rêvé de faire ${ }^{142}$, Montherlant l'a longuement méditée : avec L'Exil dès 1914 et puis, sans discontinuer de 1918 à 1924, avec des pans entiers de La Relève du matin, avec Le Songe, Le Reliquaire de la vie meilleure et le Chant funèbre. Jules César s'inscrivait dans ce programme. Ce n'est pas un hasard si à son Bricoule bis de 1921 l'écrivain a choisi d'opposer l'ex-conquérant des Gaules, et ce n'est pas non plus un hasard si les derniers mots du jeune homme renvoient à la chose publique : "Ô ma patrie, me voici seul avec toi. " Le Chant à peine paru, qui lui permettait de "clore une période de luimême ${ }^{143}$ ", Montherlant n'aura plus qu'un désir : "se désolidariser ». C'est à partir de ce moment-là qu'on verra fleurir dans son œuvre, à intervalles réguliers, une sentence héritée de Sénèque : "Plus je vais chez les hommes, plus je deviens inhumain ${ }^{144}$."

Pierre DUROISIN

480/8, chaussée de Wavre

B-1040 Bruxelles

duroisin.lenglez@scarlet.be

142 Encore qu'on ait eu tendance à minimiser les risques qu'il a courus et qui lui valurent d'être sérieusement blessé le 6 juin 1918. On eut aussi tendance à oublier ce qu'il a luimême écrit en avant-propos à son Chant funèbre: «J'ai fait la guerre moins que beaucoup d'autres " (E 177).

143 "Quand on clôt une période de soi-même, il est bien de le faire avec quelque acte pieux ", lit-on dans le préambule au Chant funèbre (E 177).

144 En 1929 dans Le dernier Retour (E 429), en 1934 dans L'Âme et son ombre (E 721), en 1948 dans un commentaire sur Le Maître de Santiago (T 539), en 1959 enfin dans Va jouer avec cette poussière (p. 33, Gallimard, 1966). La formule est extraite de la lettre 7 à Lucilius, où elle a une portée moins générale (sur ce point et, plus largement, sur le conflit entre bon plaisir et devoir chez Montherlant, voir les chapitres intitulés « Le doute et la conviction " et "La sécession" de Montherlant et l'Antiquité). 